\title{
Optimal monitoring of long-term loan contracts
}

\author{
Adrian Penalver ${ }^{1}$ \\ Working Paper 613
}

December 2016

\section{ABSTRACT}

This paper presents a theoretical model of the monitoring behaviour of a bank-intermediated financial system with a rolling portfolio of long-term loans. The projects funded by the loans are subject to persistent idiosyncratic shocks that are freely observed by the borrowers. Borrowers pay entry costs in order to produce and liquidation costs to exit and therefore are willing to pay a higher interest rate for greater security of funding. However, they also have limited liability and will make continuation choices that shift risk to the bank in the absence of monitoring. To limit its exposure to risk, the bank applies a continuation threshold of its own, labeled a covenant. The bank has an incentive to acquire information both to enforce the covenant in the current period and update its monitoring intensity in future periods. But information is costly to acquire and reduces the value of the loan contract to the borrower because it passes more of the continuation right to the bank and therefore lowers the equilibrium interest rate. The paper uses numerical methods to calculate the optimal monitoring rate and covenant threshold as well as the associated loan interest rate and default rate.

Keywords : credit standards, credit risk, monitoring

JEL classification : G21

\footnotetext{
${ }^{1}$ Banque de France, adrian.penalver@banque-france.fr

Working Papers reflect the opinions of the authors and do not necessarily express the views of the Banque de France. This document is available on the Banque de France Website. 


\section{NON-TECHNICAL SUMMARY ${ }^{2}$}

This paper considers the question of how frequently a bank should monitor the performance of a borrower when there is the possibility of credit risk. This is an important question because banks play a crucial role in the allocation of capital, particularly in Europe, and bank monitoring helps determine which firms continue and which firms are closed down. If banks monitor less frequently, then weaker firms will be allowed to continue which will reduce the efficiency of the allocation of capital and lower aggregate productivity. Understanding why banks monitor is, thus, an important theoretical question.

This paper presents a model in which entrepreneurs take out loans from a bank to finance projects of indefinite length that are subject to persistent idiosyncratic shocks. The persistence of the shocks means that entrepreneurs base their forecasts of future profitability based on their current state. The interest they pay on their bank loan is a form of fixed cost and at some point entrepreneurs will decide that they are better off shutting down their project either by liquidating it themselves or defaulting and walking away. Entrepreneurs and would-be entrepreneurs have free and perfect information about the state of their current or potential project and therefore can make fullyinformed choices every period about whether to enter, exit or continue with their project.

The bank in the model (which represents the banking system as a whole) must pay to be informed about the state of the project and will be strategic in how it gathers information. The borrowers in this model have limited liability and therefore expose the bank to credit risk if they choose to default. To protect themselves against credit risk, banks impose a continuation threshold of their own, labeled a covenant. But to enforce the covenant, the bank must know the current state of the project through monitoring.

The model structure is essentially identical to Penalver (2014) with two important differences: the covenant threshold is endogenous and banks make their monitoring choice conditional on the last known state of the project. The key result of the paper is that the monitoring schedule is downward sloping so that projects last known to be in good profitability states are monitored with lower probability than those with low profitability.

The key intuition is that the bank now has two reasons to monitor: to find out the current state of the project to enforce the covenant threshold and to update how frequently it monitors that project in future. Both incentives are decreasing in the distance to default.

\footnotetext{
${ }^{2}$ This paper has benefited considerably from the comments of Alexander Guembel and participants at a seminar at the Banque de France.
} 


\section{RÉSUMÉ : SURVEILLANCE OPTIMALE DE CRÉDIT BANCAIRE DE LONG TERME}

Cet article présent un modèle théorétique de gestion de risque et l'intensité de surveillance de crédit bancaire de long terme. Une banque s'engage avec les entrepreneurs sur des projets dont la rentabilité est soumise à des chocs stochastiques que seuls ces derniers sont en mesure d'observer. Les projets sont soumis à des coûts d'entrée pour commencer à produire et les coûts de liquidation en cas de cessation d'activité, et seront par conséquent prêt à accepter un taux d'intérêt plus élevé afin de garantir leur financement. En raison de leur responsabilité limitée, les emprunteurs ont intérêt à faire porter leurs risques de crédit sur la banque qui contrer ce risque exige en retour un niveau de rentabilité minimum. La banque acquiert des informations lui permettant d'appliquer le niveau de rentabilité minimum et ajuster son niveau de surveillance afin de limiter le risque de crédit. Les informations étant couteuse à obtenir et permettant la banque d'accroitre sa contrôle sur les projets des entrepreneurs, la valeur du contrat du point de vue de ces derniers en sera réduire ainsi que le taux d'intérêt que ceux-ci prêt à payer. Cet article utilise des méthodes numériques afin de déterminer le niveau de surveillance optimale et de rentabilité minimum ainsi que les taux d'intérêt et de défaut.

Mots-clés : normes de crédit, risque de crédit, surveillance. 


\section{INTRODUCTION}

A standard feature of any bank loan contract is a requirement for the borrower to submit to periodic monitoring of their capacity to repay. Some natural questions to ask are why such monitoring is thought to be necessary, how frequently will it take place and how does the choice of monitoring frequency affect the distribution of credit risk?

The theoretical literature has shown relatively little interest in the issue of monitoring ongoing credit relationships. Analysis instead focuses on problems at the start or the end of a fixed-term relationship, usually of only one period. Models of ex ante screening or signaling focus on the initial credit allocation decision, usually by describing how a bank can distinguish between borrowers with inherently high or low risk projects. ${ }^{1}$ It is implicit in this class of models that once a type has been given credit, no further decisions can be taken by either party that affect the probability of loan repayment.

Models of costly state verification focus instead on how creditors can enforce repayment ex post when only the borrower can observe their repayment capacity for free. ${ }^{2}$ To economise on monitoring costs, banks only do it if payment is not received. This feature is retained in multi-period models such as Clementi and Hopenhayn (2006) because shocks to borrowers are independent and therefore there is no information that is available to predict future default risk.

It follows that if monitoring of loans occurs even when a borrower continues to make interest payments, then repayment capacity must be time varying and there must be circumstances in which the creditor would like to withdraw the loan before the borrower misses a payment. ${ }^{3}$ Monitoring of ongoing loans, in other words, is about trying to catch potential defaulters before it is too late.

This sounds like common sense but it does raise the question why a bank can't rely on the self-interest of the borrower to quit if repayment capacity falls. If default is painful to the debtor, then she has an interest in ending a loan before the risks get too high. Is this not enough to align the interests of the creditor and the debtor so that the creditor can effectively delegate to the borrower the decision to end a loan prior to default?

\footnotetext{
${ }^{1}$ Seminal contributions here are Broecker (1990), Ruckes (2004), and Dell'Ariccia, Marquez, and Laeven (2010)

${ }^{2}$ Applications of the insights of Townsend (1979) to banking include Diamond (1984), Gale and Hellwig (1985) and Williamson (1986)

${ }^{3}$ Another possibility is that required payments are time and state-dependent as in the models of Border and Sobel (1987) and Monnet and Quintin (2005) but these are not loan contracts, the narrower focus of this paper.
} 
Moreover, in equilibrium borrowers can expect to have to pay higher loan interest rates for loans with greater probability of default. If the expected costs of credit risk are fully compensated, then why would a bank pay to monitor in order to reduce the equilibrium default rate? On the other hand, if credit risk is not compensated, then why would banks make risky loans at all? The case for monitoring ongoing loans is thus considerably more complex than it first appears.

Penalver (2014) presented a framework that answered many of these questions by incorporating a banking relationship into the firm dynamics model of Hopenhayn (1992). The loan contract in that model allows the bank to withdraw a loan if the profitability of the firm falls below a pre-specified level, labeled a 'covenant' threshold. However, the bank has to perform costly monitoring to discover the firm's profitability in order to enforce this termination option. The key frictions that generate a positive but less than complete monitoring rate are entry and exit costs for firms, limited liability and deadweight losses when banks liquidate firms in default.

A key simplification of that model is that the bank chooses a common monitoring rate for all firms. This is clearly highly inefficient since monitoring effort is not targeted at those firms most likely to default in the next period. It is equivalent to the bank throwing away information about the profitability of the firm, information that is valuable and was costly to obtain. A sceptical reader of that paper may well wonder whether the results are robust to more efficient monitoring. The goal of this paper is to solve the same model with a more sophisticated monitoring strategy and demonstrate that the results of the original paper continue to apply. The equilibrium monitoring strategy increases the monitoring intensity of firms last known to be weak. This enables the bank to catch more firms that fail the covenant threshold the next period and ensures that future monitoring rates are better targeted. However, the same forces as in the original paper shape the choice of average monitoring intensity and therefore the comparative static effects of different fundamental shocks remain qualitatively identical.

The remainder of the paper is organized into five sections as follows. Section 2 sets out the assumptions, repeating much of the framework of Penalver (2014), and Section 3 solves for the optimal behavior of individual agents for any given contract terms. Section 4 explains equilibrium bank behavior and the profit-maximising choice of monitoring strategy and loan covenant. Section 5 discusses the equilibrium properties of the model and Section 6 concludes.

\section{MODEL}

2.1. Environment. The economy analysed in this paper contains a measure 1 of infinitely small, ex ante identical and infinitely living risk-neutral agents and a bank. Time is 
discrete and future payoffs are discounted at rate $\beta$. In each period the agents are defined by up to three state variables. One state is an endogenously pre-determined occupation as either an entrepreneur (E) or an inventor (I). The second state is an exogenously predetermined idiosyncratic profitability level, $a$, which can be thought of as including technical productivity, consumer preferences, degree of market power and managerial talent. $a$ is drawn stochastically every period from the compact set $\{A \in \mathbb{R}: 0 \leq a \leq 1\}$. The third state variable, $\alpha$, is the last known idiosyncratic state of incumbent entrepreneurs observed by the bank. $\alpha$ conditions the monitoring rate applied by the bank and thus the expected pay-offs to the agents. The pair $(a, \alpha)$ completely defines the circumstances of each agent (and thus ex post heterogeneity). It is assumed that both parties can freely observe the initial idiosyncratic profitability state but from then on the bank must pay a cost $m$ to monitor the loan and receive a perfectly accurate report. ${ }^{4}$

2.2. Agents and production. Output in the economy is produced by firms (or projects) which have conditional gross payoffs each period of $q(a)$. Running a firm requires two units of capital and each agent is endowed with only one. It is assumed (to economise on dimensionality) that agents cannot add to or draw down on their units of capital. ${ }^{5}$ Thus the endogenous allocation of capital across profitability states is determined by the occupation decisions. In addition, market clearing (or equivalently, the balance sheet condition of the bank) requires that half the agents will have to lend their unit to the other half.

A key pay-off from making these simplifying assumptions is that the distribution of agents across profitability states is identical to the distribution of capital across profitability and ultimately the distribution of credit risk. One distribution summarises all heterogeneity in the model. Throughout their infinite lives, agents cycle stochastically but endogenously between the two occupations. The equilibrium distributions can, therefore, be interpreted either as a cross-section of the population at any point in time or a density measure of the time any agent spends in any interval of the idiosyncratic state-space during their infinite life.

\footnotetext{
${ }^{4}$ The assumption that the bank observes the initial state for free is for simplicity and ensures that every loan starts with a known state. Nothing of substance rests on this assumption.

${ }^{5}$ It is trivial to extend the model to include heterogeneity in endowment, project or borrowing size so these normalisations are uncontroversial. It is a much more serious restriction to rule out time varying investment and time varying credit. Technically the possibility of wealth accumulation creates the wellknown problem that some agents could save their way out of the model. More specifically in the context of this model, decisions to apply for credit or pay down debt could provide free information to the creditor about the idiosyncratic state of the project and thereby eliminate the need to undertake costly monitor. This signaling could then by muddied by assuming adjustment costs for investment and debt that create zones of inactivity. Including these aspects would substantially complicate what is already a complex model. It is not clear that the main qualitative results of the paper would be affected.
} 
Agents must pay to switch from one occupation to the other. Inventors must pay startup costs $C$ to become an entrepreneur. ${ }^{6}$ Inventors, therefore are weighing up paying $C$ to enter based on their current profitability draw $a$ or waiting another period for a possibly better draw. ${ }^{7}$ An entrepreneur must pay $L$ to liquidate her project and quit to become an inventor. These liquidation costs might be pecuniary such as termination pay, liquidating stock at below cost and administrative costs or non-pecuniary such as lost human capital and reputation. ${ }^{8}$

The consumption side of this economy is not explicitly modeled but it is implicit from the assumption of no capital accumulation or decumulation that agents consume their current period net pay-offs. The various costs in the model are assumed to be resource costs in the sense that they are not a source of income for other agents in the model. Finally, all decisions in the model are based on the relative value of different options and no options are ruled out because of incapacity to pay. This means that decisions depend only on the idiosyncratic states which helps keep the model comparatively simple.

2.3. The bank. The bank is an independent player in the model. It has no capital of its own to simplify the balance sheet condition but nothing of substance would change through the inclusion of an equity base. The bank performs three roles in the model. It is an intermediary that diversifies across idiosyncratic risks. Since there are no aggregate shocks and no possibility of aggregate capital accumulation, the bank solves a timeless or static optimisation problem. Complete diversification and constant profitability allows the bank to offer risk-free deposits. The second task performed by the bank is credit monitoring. The bank has an interest in the cross-sectional distribution of firms because this determines equilibrium credit risk. The bank's monitoring strategy and covenant threshold shape this equilibrium distribution and thus the allocation of credit in the economy. Finally, the bank resolves firms that default and go bankrupt. It is an important assumption that the bank cannot salvage as much from a bankrupt firm as the entrepreneur could if she liquidated her firm voluntarily in the same idiosyncratic state. In other words, there are excess costs of bankruptcy that are borne by the bank because in this set-up it is the residual claimant. The importance of this assumption is described in more detail in the section on the equilibrium properties of the model.

\footnotetext{
${ }^{6}$ Start up costs are large in many countries. In Djankov, Porta, Lopez-De-Silanes, and Shleifer (2002) just the official costs of entry range from $0.5 \%$ of per capita GDP in the US to $460 \%$ of per capita GDP in the Dominican Republic.

7 This is similar to the way wage offers are received in labour search models such as McCall (1970).

8 Ramey and Shapiro (2001) describe the heavy discounts on machinery sold during the closure of aircraft manufacturing plants.
} 
The bank offers inventors a deposit contract in which they can store their unit of capital. Inventors can withdraw their deposit in any period and will do so when they wish to switch to being an entrepreneur. Deposits pays an exogenously set interest rate, $\tau .{ }^{9}$

The bank is assumed to offer entrepreneurs a relational loan contract. Entrepreneurs have the right to pay back their loan in any period and will do so whenever they choose to liquidate their firm. On the other side, the bank has the right to monitor the firm and demand repayment if net profits, $(q(a)-\rho)$, is below a covenant threshold $\zeta$. It is relational in the sense that the loan continues in the absence of a decision to end it by either party. The bank monitors stochastically according to a schedule $\varphi(\alpha)$ that is contingent on the last known state of the firm. All loans pay a common interest rate, $\rho$.

It is important to be clear that these are not optimal contracts based on mechanism design. The forms of these contracts are intended to capture the main features of actual deposit and loan contracts in a way that can be applied recursively. Optimality is used in this paper to describe the profit maximising parameters of these contract forms. Specifically, the bank is choosing its monitoring schedule, $\varphi(\alpha)$, the loan interest rate, $\rho$, and the covenant threshold $\zeta$ in order to maximise its equilibrium profit. For notation convenience these loan terms are summarised as $\psi=\{\rho, \varphi(\alpha), \zeta\}$.

2.4. Timing. The timing of shocks and decisions each period is as follows:

(1) The agents enter each period in their pre-determined endogenous occupation states, $E$ or $I$. Entrepreneurs have a pre-existing idiosyncratic state $a$ and last observed idiosyncratic state $\alpha$. (Notationally, states determined in the previous period will be denoted $x$, states determined in the current period $x^{\prime}$ and states determined next period $x^{\prime \prime}$.)

(2) The agents make their occupation choices for the current period. Entrepreneurs who choose to quit repay their bank loans and inventors who enter take out a loan. By assumption these are both of size 1 .

(3) Idiosyncratic profitability of existing evolves stochastically according to the conditional cumulative distribution $F\left(a^{\prime}, a\right)$. Inventors draw a new idea $a^{\prime}$ from $G(a)$.

(4) Then payoffs are received. Entrepreneurs have the option of declaring themselves bankrupt, at a cost $B$, in return for avoiding the current net pay-off of the project. Entrepreneurs thus receive either $q\left(a^{\prime}\right)-\rho$ or $B$. Inventors receive their deposit interest. Bankrupt entrepreneurs become inventors next period and are indistinguishable from other inventors. ${ }^{10}$

\footnotetext{
${ }^{9}$ Since the bank is a monopolist, it would like to push the deposit rate as low as possible. $\tau$ can be thought of as the value of an alternative storage option or as being set by a monetary authority.

10 It is just convenient to recycle defaulters in this way. Nothing of any substance would change by assuming defaulters are excluded forever but new inventors are born at the same steady-state rate.
} 
(5) The bank monitors each loan in its portfolio with probability $\varphi(\alpha)$.

(6) Those who are monitored and found to have net profits $q(a)-\rho$ below the covenant threshold $\zeta$ have their loans recalled. This condition defines implicitly a bank exit threshold $q\left(a^{T}\right)=\rho+\zeta$. The bank updates the last known state of those who it allows to continue. The borrower naturally knows that this update has taken place. After the option to monitor, the bank has a last observed state $\alpha^{\prime}$. Like those going bankrupt, those whose loans are recalled become inventors in the following period.

(7) Agents then exit the period in an occupational state, have an idiosyncratic profitability state $a^{\prime}$ and last observed state $\alpha^{\prime}$.

2.5. Technical assumptions. The following assumptions on the stochastic processes and profit function are made:

I: (i) $F\left(a^{\prime}, a\right)$ is continuous in $a$ and $a^{\prime}$; (ii) profitability shocks are persistent, so $F\left(a^{\prime}, a\right)$ is strictly decreasing in $a$; but (iii) profitability shocks eventually die out and the monotone mixing condition is satisfied: $F^{n}(\epsilon, a)>0 \forall \epsilon$ for some $n$ where $F^{n}(\epsilon, a)$ is the conditional probability distribution of profitability in $n$ periods time given a. So from any given level of profitability, it is possible to transit to any other interval of the profitability space in a finite number of periods. Since there are exit thresholds, this assumption implies that all projects will almost surely close at some future point.

II: $q(a)$ is (i) continuous; and (ii) strictly increasing in $a$.

III: $G(a)$ is continuous and independently and identically distributed.

\section{EQUILIBRIUM BEHAVIOUR OF THE AGENTS}

This section describes the optimal responses of the agents to a given bank contract, $\psi{ }^{11}$ Given the structure of the model and the assumptions I-III the agents face well-defined Markov decision problems.

3.1. Entrepreneurs. Those that enter the period as entrepreneurs can make two decisions. The first is whether to exit or continue and the second, if they decide to continue, is whether or not to default once the payoff is revealed. The expected outcome of the second choice conditions the first.

11 To save on notation the dependence of all functions on $\psi$ is supressed in this section except for the definitions of the threshold functions. 
The default decision occurs after the revelation of the shock $a^{\prime}$. The value of absorbing the pay-off and continuing into the next period as an entrepreneur is

$$
V_{C}\left(a^{\prime}, \alpha\right) \equiv q\left(a^{\prime}\right)-\rho+\beta E\left[V\left(E, a^{\prime}, \alpha^{\prime}\right) \mid \alpha\right]
$$

where $E\left[V\left(E, a^{\prime}, \alpha^{\prime}\right) \mid \alpha\right]$ is the expected value of being an entrepreneur at the continuation decision point next period conditional on idiosyncratic state $a^{\prime}$ and last observed state $\alpha$. It is an expected value because there is the random probability of being monitored by the bank before the continuation decision point arrives in the following period. This probability of being monitored depends on $\alpha$ because this conditions the probability of being monitored.

$$
\begin{aligned}
E\left[V\left(E, a^{\prime}, \alpha^{\prime}\right) \mid \alpha\right] & =(1-\varphi(\alpha)) V\left(E, a^{\prime}, \alpha\right) \\
& +\varphi(\alpha)(1-\mathbf{1}(a)) V\left(E, a^{\prime}, a^{\prime}\right) \\
& +\varphi(\alpha) \mathbf{1}(a)\left[V\left(I, I^{\prime}\right)-L\right]
\end{aligned}
$$

$E\left[V\left(E, a^{\prime}, \alpha^{\prime}\right) \mid \alpha\right]$ is composed of three parts. If the bank does not monitor then the entrepreneur continues to the decision point in the next period and the last known state is not updated and so remains at $\alpha$. This is expressed in the first term. If the bank monitors the loan and it is above the covenant threshold (the binary state represented by $1-\mathbf{1}(a)$ ), then the entrepreneur continues to the decision point at the next period with an updated last known state $\alpha^{\prime}=a^{\prime}$. This is expressed in the second term. Finally, if the loan is monitored and is found to be below the covenant threshold, then the entrepreneur pays the liquidation cost and starts the next period as an inventor. ${ }^{12} V\left(I, I^{\prime}\right)$ is the value of starting the period as an inventor and choosing to remain an inventor for the following period. It thus represents the case of a new inventor who has to wait to receive their first idea. This is represented in the third term. The value of being a continuing inventor next period is given by

$$
V\left(I, I^{\prime}\right)=\tau+\beta \int_{0}^{1} V\left(I, a^{\prime}\right) G\left(a^{\prime}\right)
$$

This expectation is not conditioned on $a$ because $G\left(a^{\prime}\right)$ is i.i.d..

The value of defaulting is

$$
V_{D}=-B+\beta V\left(I, I^{\prime}\right)
$$

$V\left(I, I^{\prime}\right)$ is a scalar in equilibrium and therefore so is $D$. In making her default decision, the entrepreneur is comparing the value of equations (1) and (2) will naturally choose

12 Since the entrepreneur is being forced to exit after profits have been taken and the loan interest payment made for the period, her choice is between exiting at cost $B$ or $L$. Since $L<B$, the entrepreneur will always prefer to liquidate and exit voluntarily. 
$\max \left\{V_{C}\left(a^{\prime}, \alpha\right), V_{D}\right\}$. Provided $E V\left(E, a^{\prime}, \alpha^{\prime}\right)$ is non-decreasing in $a^{\prime}$, which it will be, then $\max \left\{V_{C}\left(a^{\prime}, \alpha\right), V_{D}\right\}$ implicitly defines a unique ${ }^{13}$ default threshold $a_{D}(\psi, \alpha)$ for each $\alpha$ by

$$
q\left(a_{D}(\psi, \alpha)\right)+\beta E V\left(E, a_{D}(\psi, \alpha), \alpha, \psi\right)=\rho-B+\beta V\left(I, I^{\prime}, \psi\right)
$$

Now we can consider the continuation decision at the start of the period before the evolution of the idiosyncratic state is revealed. Given the monotonicity of the default decision and the stochastic process for the idiosyncratic state, $F\left(a^{\prime}, a\right)$, the expected value of remaining an entrepreneur conditional on $(a, \alpha)$ can be expressed as

$$
\begin{aligned}
V\left(E, a, \alpha, E^{\prime}\right)= & E\left[\max \left\{V_{C}\left(a^{\prime}, \alpha\right), V_{D}\right\} \mid a, \alpha\right] \\
= & \int_{a_{D}}^{1}\left\{q\left(a^{\prime}, \alpha\right)-\rho+\beta E\left[V\left(E, a^{\prime}, \alpha^{\prime}\right) \mid \alpha\right]\right\} F\left(d a^{\prime}, a\right) \\
& +\left[\beta V\left(I, I^{\prime}\right)-B\right] \int_{0}^{a_{D}} F\left(d a^{\prime}, a\right)
\end{aligned}
$$

The value for an entrepreneur of exiting voluntarily and switching to being an inventor in the current period is equivalent to

$$
V\left(E, I^{\prime}\right)=-L+V\left(I, I^{\prime}\right)
$$

which will also be a scalar in equilibrium and is independent of $a$ and $\alpha$. The entrepreneur will choose the best of the two options and since $V\left(E, I^{\prime}\right)$ is a scalar and $V\left(E, a, \alpha, E^{\prime}\right)$ will be strictly increasing in $a$ for any $\alpha$, there is again a unique implied threshold switching value for exiting voluntarily conditional on $\alpha$. The exit threshold, $a_{X}(\psi, \alpha)$, is implicitly defined by

$$
E\left[\max \left\{V_{C}\left(a^{\prime}, \alpha, \psi\right), V_{D}\right\} \mid a_{X}(\psi, \alpha)\right]=-L+V\left(I, I^{\prime}, \psi\right)
$$

Finally, the value of being an entrepreneur at the continuation decision point is the maximum of the two options:

$$
V(E, a, \alpha)=\max \left\{V\left(E, I^{\prime}\right), V\left(E, a, \alpha, E^{\prime}\right)\right\}
$$

\footnotetext{
13 Uniqueness follows from the assumption that $q(a)$ is strictly increasing in $a$.
} 
3.2. Inventors. Inventors only make an entry or continuation decision. The value of entering for a given value of $a$ is identical to that of a continuing entrepreneur with the same idiosyncratic state net of the start up costs, $C$, and $\alpha=a$.

$$
V\left(I, a, E^{\prime}\right)=V\left(E, a, a, E^{\prime}\right)-C
$$

The value of remaining an inventor $V\left(I, I^{\prime}\right)$ has already been defined and the value of being an inventor at the decision point is the maximum of the two options:

$$
V(I, a)=\max \left\{V\left(I, I^{\prime}\right), V\left(I, a, E^{\prime}\right)\right\}
$$

As in the previous decisions, one of the options, $V\left(I, I^{\prime}\right)$, is a known scalar and the other, $V\left(I, a, E^{\prime}\right)$, is strictly increasing in $a$. Therefore there is a unique entry threshold, $a_{E}(\psi)$ implicitly defined by

$$
V\left(E, a_{E}(\psi), a_{E}(\psi), E^{\prime}\right)-C=V\left(I, I^{\prime}\right)
$$

which can be re-written as

$$
E\left[\max \left\{V_{C}\left(a^{\prime}, a_{E}(\psi), \psi\right), V_{D}\right\} \mid a_{E}(\psi)\right]=C+V\left(I, I^{\prime}, \psi\right)
$$

The results of this section are summarised in the following Propositions

Proposition 1-Given Assumptions I, II and III and a banking contract $\psi$, unique, bounded and mutually consistent functions $V(E, a, \alpha ; \psi, V(I))$ and $V(I, a ; \psi, V(E))$ exist.

Proof. The details of the proof are in the appendix.

Proposition 2- The value functions in Proposition 1 yield unique and continuous functions in $\psi$ for the entry threshold $a_{E}$ and exit thresholds $a_{X}(\alpha) . a_{E}(\psi)$ and $a_{X}(\psi, \alpha)$ are both strictly increasing in $\psi$.

Proof. The details of the proof are in the appendix.

It turns out that the key condition that proves the second part of Proposition 2 is that $\beta<1$. The intuition for this condition is worth understanding. In this model, agents cycle endogenously but stochastically between being inventors (depositors) and entrepreneurs (borrowers) throughout their infinite lives. The equilibrium cross-sectional distribution across idiosyncratic states is also the proportion of time that each agent will spend in any interval of the profitability set throughout their life. As $\beta \rightarrow 1$, the agent comes to value each of these future states with equal weight and the current state becomes of vanishing relative importance. The value functions of all agents converge towards a common value 
(although in the limit this explodes for $\beta=1$ ). This value function is common between inventors and all entrepreneurs.

As $\beta \rightarrow 1$, a rise in $\rho$ decreases all the value functions by about the same amount. Without any difference in the relative value of being in different endogenous states, there is no change in behaviour and thus no effect on the switching thresholds. With $\beta<1$, the current state has more weight in the value function than the common expected future of all agents. Only with $\beta<1$ does the current state matter than any other period. In this case, an increase in $\rho$ reduces the common expected future value of all agents but reduces the value of being an entrepreneur in the current period because this rate is paid now. This reduces the relative value of being an entrepreneur and raises the threshold value of the idiosyncratic state at which the marginal entrepreneur is just indifferent between continuing or exiting.

This section appears very complicated but is intuitively very simple. Entrepreneurs are choosing whether to continue, exit voluntarily or default. The bank also has the option to monitor each loan and withdraw funding (and thus shut down the firm) for all those found to be below a covenant threshold. The inventors are choosing whether to enter production or not depending on their initial idiosyncratic draw. These various options have a natural ordering so that there are unique values of $a$ at which the agents switch from one option to another. These thresholds, which completely summarise the behaviour of the agents, are influenced by the contract terms of the loan and what was the last state observed by the bank. Intuitively, the less attractive the terms of the loan contract, the higher the various thresholds. For example, if the loan interest rate is higher, then entering becomes less attractive and inventors will only be willing to do so at a higher value of $a$.

3.3. Cross-sectional distribution of firms. Define $H(\psi)$ as the joint distribution of firms by current idiosyncratic state and last known state just before the idiosyncratic shock. The state variables at this point are $(a, \alpha)$. From the current period to the next, $H(\psi)$ evolves into $H^{\prime}(\psi)$ in three ways:

(1) There will be those firms that are not monitored and can make their own exit decisions. Some will default and some will exit voluntarily at the beginning of the next period. Since the voluntary exit threshold is above the default threshold in any sensible calibration, it is the voluntary exit threshold that truncates the ex post distribution. Continuing firms not monitored by the bank retain their last known state, $\alpha$.

(2) There will be those firms that are monitored at stage 5. From the timing assumption, these will only be firms that have not defaulted. If $\alpha^{\prime} \geq a^{T}$ then the firm continues to the next period and if it is not, the loan is recalled and the firm will 
disappear from the distribution. For a monitored firm, the bank updates its last known state for that firm from $\alpha$ to $a^{\prime}$ as the monitoring is assumed to be perfectly accurate.

(3) New firms will enter. These will be any inventors receiving a draw of $a^{\prime} \geq a_{E}(\psi)$. From the assumption that the initial idiosyncratic state can be observed for free, $\alpha^{\prime}=a^{\prime}$.

These three processes can be described using two bounded linear operators $\hat{P}(\psi)$ and $g(\psi)$ (following Hopenhayn (1992)) . For borel sets $Q \times R$ in $A \times A$ define

$$
\hat{P}(a, \alpha, Q, R ; \psi)=\mathbf{1}(\alpha, R)(1-\varphi(\alpha)) \int_{Q \cap Y(\psi, \alpha)} F(d q, a)+\varphi(\alpha) \int_{Q \cap R \cap Z(\psi, \alpha)} F(d q, a)
$$

and

$$
g(Q, R, \psi)=\int_{Q \cap R \cap W(\psi)} G(d s)
$$

where $\mathbf{1}(\alpha, R)$ is an indicator function taking the value 1 if $\alpha \in R$ and 0 otherwise, $W(\psi)=$ $\left\{a^{\prime}: a^{\prime} \geq a_{E}(\psi)\right\}, Y(\psi, \alpha)=\left\{a^{\prime}: a^{\prime} \geq a_{T}(\psi, \alpha)\right\}$ and $Z(\psi, \alpha)=\left\{a^{\prime}: a^{\prime} \geq a_{X}(\psi, \alpha)\right\}$. The first term in $\hat{P}$ describes the evolution of the unmonitored firms and the second term describes the evolution of the monitored firms. $g(\psi)$ describes the entry distribution. $\hat{P}(a, X ; \psi)$ defines a bounded linear operator on the space of positive bounded measures defined by $\hat{P} H(Q, R)=\int \hat{P}(a, \alpha, Q, R ; \psi) H(d a)$ for all borel sets $Q \times R$ in $A \times A$ with operator norm $\|\hat{P}\| \leq 1$.

With these operators, the evolution of the joint distribution of firms, $H(\psi)$, can be summarised in the following transition function:

$$
\left.H^{\prime}(\psi)=\hat{P}(\psi) H^{(} \psi\right)+N g(\psi)
$$

for an arbitrary measure of potential entrants $N$.

An invariant steady state distribution $\bar{H}(\psi)$ occurs if

$$
\bar{H}(\psi)=P(\psi) \bar{H}(\psi)+N g(\psi)
$$

PROPOSITION 3- For each $\psi$ and arbitrary $N$ there is a unique invariant distribution, $\bar{H}(\psi)$.

This, too, is a difficult section to digest but the intuition is again fairly simple. Incumbent firms are moving in two dimensions, their idiosyncratic state, $a$, and the last known state observed by the bank, $\alpha$. The rate at which they are monitored is determined by $\alpha$ and the pair $(a, \alpha)$ determines the exit choices. The cross-sectional distribution of incumbent firms is evolving according to the idiosyncratic shock process and the exit decisions of both the entrepreneurs and the bank. The cross-sectional distribution is refreshed by the entry of new firms which is scaled by $N$. An invariant distribution occurs when this overall cross-sectional distribution remains unchanged from one period to the next. 
FIGURE 1. Illustrative Invariant Distribution

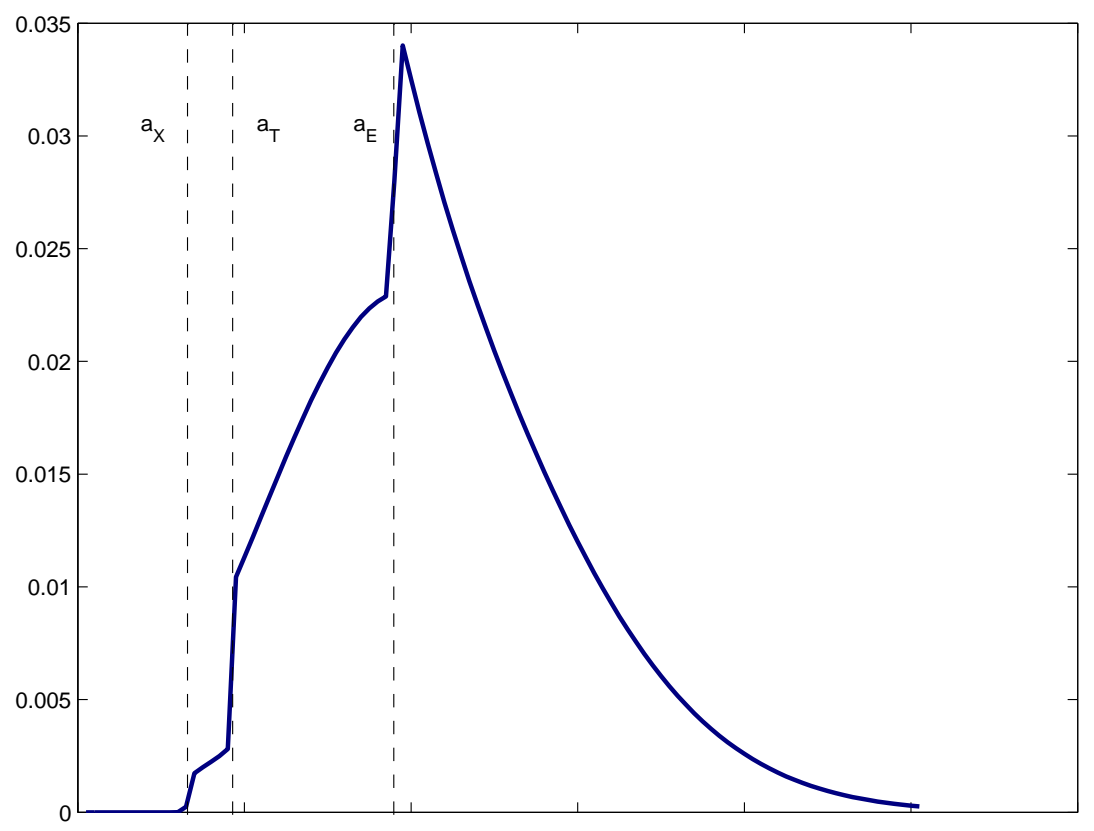

Note: The figure presents the distribution function across idiosyncratic profitability states $a$.

\section{EQUILIBRIUM CHOICES OF THE BANK}

4.1. Illustrative numerical example. Before turning to the decision of the bank, it is useful to illustrate an example of an invariant distribution derived from the model and decompose its transition. Details of the derivation of the model are in the appendix. The model was calibrated to deliver roughly sensible values for the endogenous variables but there is no intention to match precisely empirical data.

Figure 1 illustrates $\bar{H}(\psi)$, the distribution just before the idiosyncratic shock. It is easy to see the influence of the three sets of behavioural thresholds on the distribution. Indeed the thresholds are so similar that they can be summarised using common labels in the figure.

There are no entrepreneurs in the distribution below $a_{X}$ because this is the minimum participation threshold. Between $a_{X}$ and $a_{T}$ we have entrepreneurs that are in breach of the loan covenant but have escaped monitoring and there is a concentration of entrepreneurs just above the entry threshold, $a_{E}$. There is a long right tail to this distribution. These are entrepreneurs who have either entered with a very high initial profitability level or entered and subsequently experienced predominantly positive profitability shocks.

Figure 1 also helps draw out the importance of the start-up and liquidation costs in driving the results of the model. If we combine equations (4) and (5) which determine 
FIGURE 2. One Period Transition of the Invariant Distribution

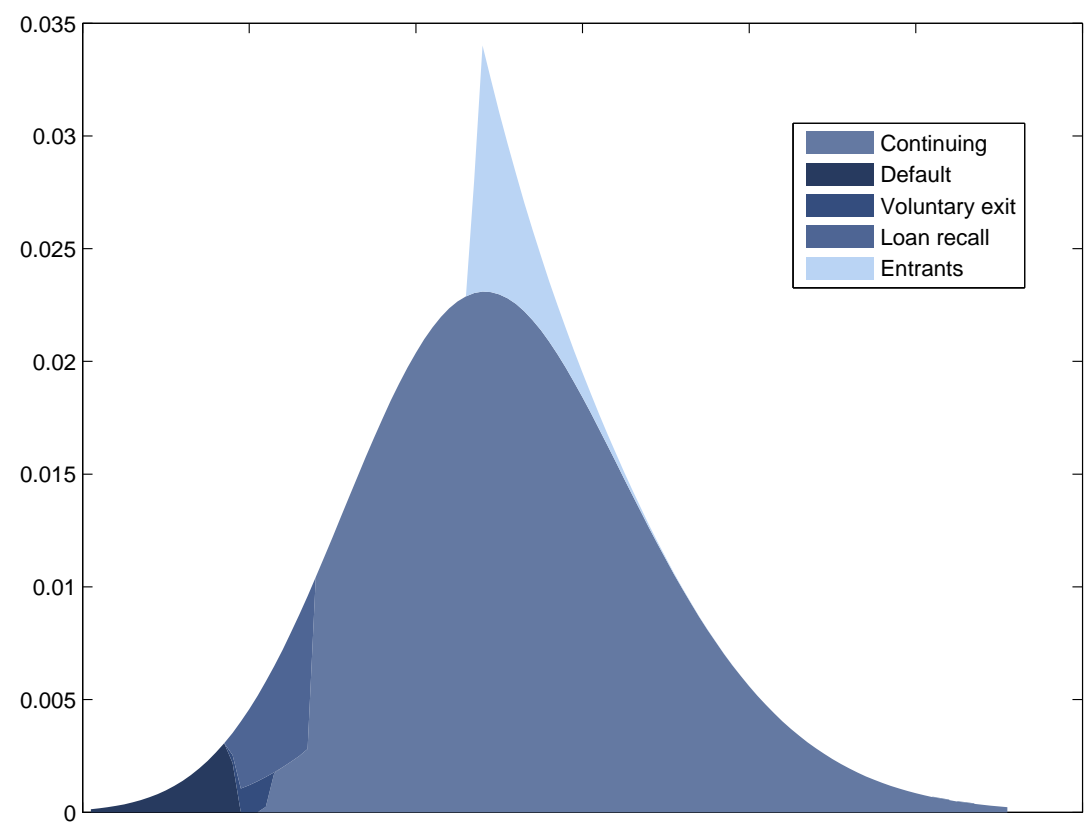

the entry and exit thresholds and ignore the dependence of the monitoring rate on $\alpha$, then we obtain

$$
E\left[\max \left\{V_{C}\left(a^{\prime}, \psi\right), V_{D}\right\} \mid a_{X}(\psi)\right]=E\left[\max \left\{V_{C}\left(a^{\prime}, \psi\right), V_{D}\right\} \mid a_{E}(\psi)\right]-C-L
$$

from which it can be easily seen that if $C=L=0$, then $a_{E}(\psi)=a_{X}(\psi)$. Since the covenant threshold is only relevant in the interval $\left[a_{X}(\psi), a_{E}(\psi)\right]$, if we have $C=L=0$ and $a_{E}(\psi)=a_{X}(\psi)$, then $a_{T}$ is redundant and so is bank monitoring and thus $\alpha$ is irrelevant, validating its initial exclusion. In other words, if $C=L=0$, then there is no incentive for bank monitoring even though there is a positive probability that profitability falls below the default threshold, $a_{D}$ because in this frictionless entry and exit case, borrower behaviour is completely aligned with the interests of the bank. Borrowers only continue in situations in which they would also wish to enter. Frictionless entry and exit always selects the most profitable firms given the profitability processes which in turn has the lowest possible credit risk. So asymmetry of information has no bite when exit and entry is costless. ${ }^{14}$ This ability to rely on borrower behaviour breaks down when there are entry and exit costs because private choice by borrowers no longer selects the lowest credit risk portfolio. By setting a covenant threshold and monitoring stochastically, the bank can alter the distribution of credit risk.

Figure 2 illustrates the one period transition of the distribution in Figure 1. Looking from right to left, one can see that the upper tail of the distribution is entirely driven by

\footnotetext{
14 With a single $F$ process and bankruptcy costs, the bank does not need to engage in ex ante screening or ex post monitoring in this setting.
} 
the presence of a small number of incumbent entrepreneurs experiencing positive shocks. Since on average entrepreneurs with positive profitability experience a reversion towards the mean (of zero), there is a noticeable deterioration in the average quality of continuing entrepreneurs. ${ }^{15}$ The distribution is refreshed by the entry of new entrepreneurs clustered above the entry threshold. Moving further to the left, a number of entrepreneurs fall below the threshold $a_{T}$ but are above $a_{X}(\psi)$. These are the entrepreneurs who want to continue but are in breach of the loan covenant. $\varphi(\alpha)$ proportion of these entrepreneurs are monitored, have their loans recalled and exit and $1-\varphi(\alpha)$ are able to continue. Moving further to the left, there are entrepreneurs who fall below $a_{X}(\psi)$ but above $a_{D}(\psi)$ and exit voluntarily. Finally, there is a portion of the distribution that falls below $a_{D}(\psi)$ and defaults.

4.2. Equilibrium bank behaviour. We can now turn to the bank's choice of parameters in the loan contract $\psi=\{\rho, \varphi(\alpha), \zeta\}$. Proposition 3 asserted that there is a unique invariant distribution for any loan contract, $\psi=\{\rho, \varphi(\alpha), \zeta\}$ and measure of inventors, $N$. The bank, however, is constrained in its choice of loan contract by the need to finance its loans by deposits. ${ }^{16}$ Using the simplifying assumption made earlier that all agents have a fixed unit of capital but projects require 2 units, it follows that there must be as many borrowers as depositors. With measure 1 of agents, the funding constraint faced by banks in equilibrium is:

$$
\bar{H}(A, A ; \psi)=\frac{1}{2}
$$

Although choosing an optimal $\{\rho, \varphi(\alpha), \zeta\}$ triplet is a joint decision, for ease of explanation (and proof) it will be assumed that the bank uses the loan rate to equilibrate its balance sheet and then uses the monitoring schedule, $\varphi(\alpha)$, and loan covenant threshold, $\zeta$, to maximise profits.

PROPOSITION 4- There is a unique value $\tilde{\rho}$ that satisfies the balance sheet constraint, equation (8), for given schedule $\varphi(\alpha)$ and given value for $\zeta$.

This is a very intuitive proposition. From Proposition 3, there is a unique invariant distribution given $\varphi(\alpha)$ and $\zeta$ for any $\rho$ and $N=\frac{1}{2}$. The integral size of that unique distribution is continuous in $\rho$ so if it is too big - ie the bank faces an excess demand for loans - then raising the borrowing rate simultaneously reduces the demand for new loans (by increasing $a_{E}$ ), increases the incentive for existing borrowers to repay and exit

\footnotetext{
${ }^{15}$ This average deterioration is not a contrived or calibrated phenomenon but arises because selfselection and competition ensure that most incumbent firms were profitable in the previous period and profitability is a mean-reverting process.

16 The level of equity funding is not relevant in this model.
} 


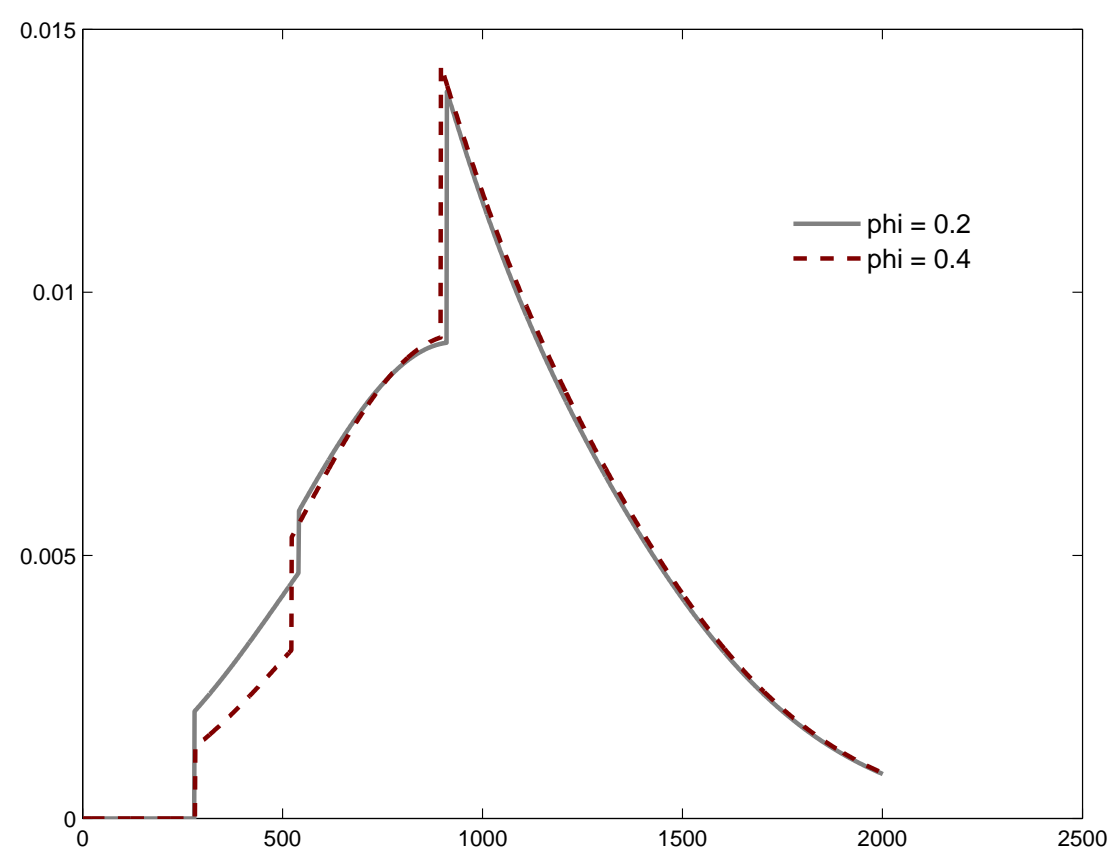

FIGURE 3. Equilibrium Effect of Higher or Lower Monitoring

production voluntarily (an increase in all the $a_{X}(\alpha)$ simultaneously) and effectively tightens the loan covenants (by increasing $a_{T}$ ). These effects work on both sides of the balance sheet by reducing loans and increasing deposits. Uniqueness follows from continuity and monotonicity of the behavioural functions and the intermediate value theorem. With $\rho$ a function of $\varphi(\alpha)$ and $\zeta$, we can denote the subset of invariant balance sheets, $\bar{H}$, which satisfy the balance sheet constraint as $\tilde{H}(A, \rho(\varphi(\alpha), \zeta), \varphi(\alpha), \zeta)$.

Crucially, not all invariant distributions that satisfy the balance sheet constraint are equivalent from the point of view of the bank. Figure 3 illustrates what is at stake in the simplified setting in which $\varphi$ is set independently of $\alpha$. Figure 3 plots the distributions that satisfy the balance sheet constraint for two different monitoring rates $\varphi=0.2$ and $\varphi=0.4$.

A lower $\varphi$ with the same $\rho$ would not satisfy the balance sheet constraint. Directly, more firms continue in breach of the covenant than otherwise and this expands the measure of borrowers. Indirectly, since all incumbent firms have some positive probability of ending up in the interval between $\left[a_{X}(\rho), a_{T}(\rho)\right]$, a lower monitoring rate increases the incentive to be a borrower at all idiosyncratic profitability levels. More incumbent firms would want to continue and more firms would want to enter. In the context of this model, there would be a reduction in the supply of savings and an increase in loan demand.

To bring these back into line, the bank must raise the loan interest rate, a rate that is applied to all borrowers. However, borrowers who are currently in the interval $\left[a_{X}(\rho), a_{T}(\rho)\right]$ 
gain from a lower $\varphi$ and higher $\rho$ because it affects their immediate survival probabilities. Borrowers far from the covenant threshold, on the other hand, are net losers. Whilst they will almost certainly enter the interval $\left[a_{X}(\rho), a_{T}(\rho)\right]$ at some point in the future, the value of increased survival probability is discounted. Since there is a relative benefit to incumbents in the interval $\left[a_{X}(\rho), a_{T}(\rho)\right]$ but the integral measure of the whole distribution of borrowers must be $\frac{1}{2}$, there must be less borrowers elsewhere in the distribution. Although it is perhaps not easy to see, the entry threshold is higher when the monitoring rate is lower and there are marginally less firms at all idiosyncratic profitability levels above the entry threshold. Overall, a lower $\varphi$ but higher $\rho$ slows down the turnover rate of firms and increases the measure of firms in the lower tail of the distribution. Since the distribution of firms is identical to the distribution of borrowers (since all firms borrow the same amount by assumption) and default risk is decreasing in idiosyncratic profitability, we have the intuitive result that a lower monitoring rate reduces the credit quality of the bank's loan portfolio.

Having show intuitively the main trade-offs in a simpler setting, we can now state the decision problem of the bank in the more complex setting more formally. To limit notation, define $\tilde{\psi}=\{\varphi(\alpha), \zeta\}$ as a given pair of monitoring schedule and covenant threshold. And define $F \tilde{H}(A, \hat{\alpha} ; \tilde{\psi}) \equiv \int_{A} F(a l, a) \tilde{H}(d a, \hat{\alpha} ; \tilde{\psi})$ as the cross-sectional distribution of firms after the shock from the segment $\tilde{H}(A, \hat{\alpha} ; \tilde{\psi})$ of the balance sheet consistent invariant distribution $\tilde{H}(\rho(\tilde{\psi}), \tilde{\psi})$. $F \tilde{H}(A, \hat{\alpha} ; \tilde{\psi})$ is the ex post distribution of firms whose last known state was $\hat{\alpha}$ from the balance sheet consistent invariant distribution conditional on $\tilde{\psi}$.

The profits of the bank depend on this ex post invariant distribution through the following equation.

$$
\begin{aligned}
\Pi= & \rho(\tilde{\psi}) \iint_{a_{D}(\tilde{\psi}, \alpha)}^{1} F \tilde{H}\left(d a^{\prime}, \alpha ; \tilde{\psi}\right) d \alpha \\
& -\iint_{0}^{a_{D}(\tilde{\psi}, \alpha)} \lambda\left(a^{\prime}\right) F \tilde{H}\left(d a^{\prime}, \alpha ; \tilde{\psi}\right) d \alpha \\
& -\varphi(\alpha) m \iint_{a_{X}(\tilde{\psi}, \alpha)}^{1} F \tilde{H}\left(d a^{\prime}, \alpha ; \tilde{\psi}\right) d \alpha \\
& -\tau \frac{1}{2}
\end{aligned}
$$

The first line represents the loan interest payments the bank will receive from all firms who evolve into profitability states above the default threshold $a_{D}(\rho(\tilde{\psi}), \tilde{\psi}, \hat{\alpha})$. The second line represents the excess loss given default bank arising from the assumption that the bank is relatively inefficient at liquidating firms, a factor parameterised by $\lambda(a)$. The third line represents the monitoring costs $m$ on all non-defaulting firms in proportion to the monitoring rate $\varphi(\hat{\alpha})$. Net revenue on lending is be the integral of these across all 
FIGURE 4. Equilibrium Profits for Different Choices of Monitoring Intensity and covenant threshold

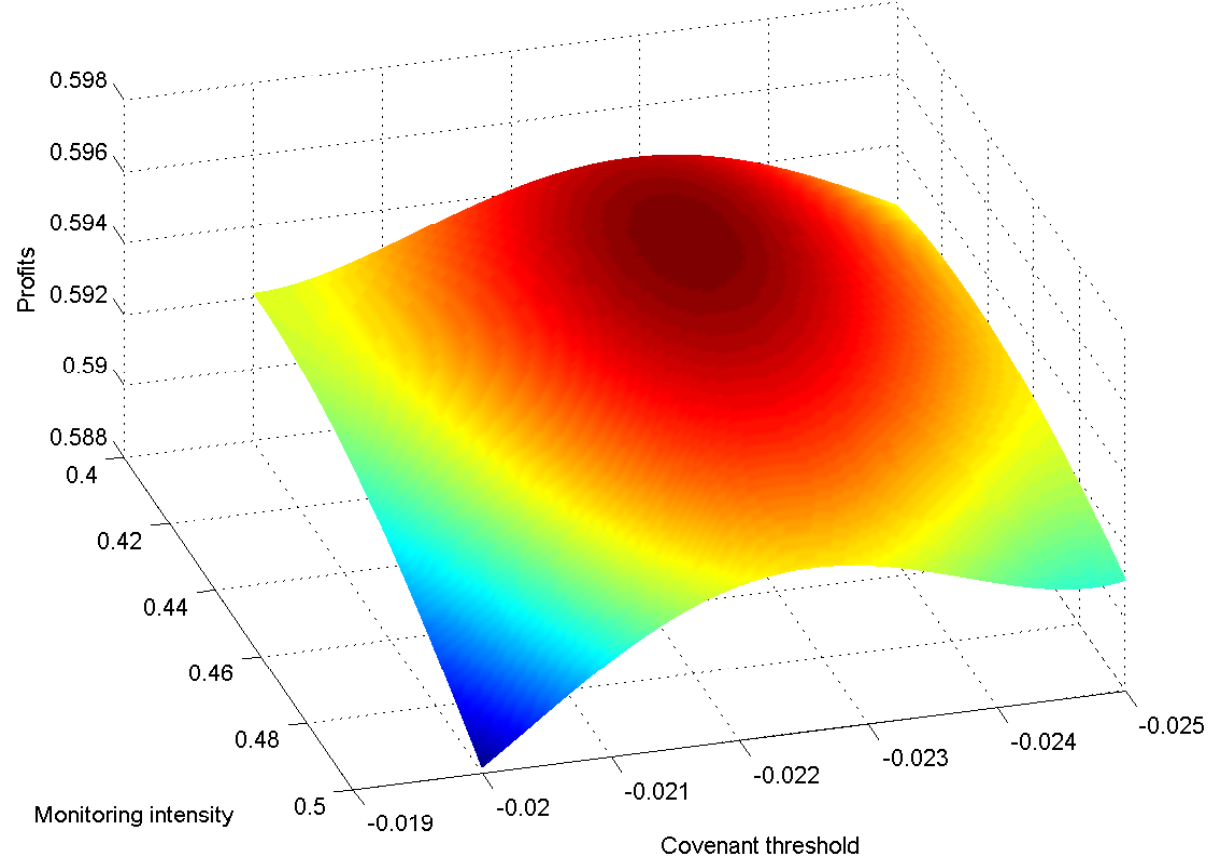

the last observed states, $\alpha$. Finally, the bank will have to pay $\tau \frac{1}{2}$ in equilibrium as deposit interest. The objective of the bank is to

$$
\max \Pi
$$

Again the mathematical complexity obscures a relatively intuitive problem. The bank is trying to pick its credit standards - how frequently to monitor loans given the last known state and the covenant threshold - which together allow the bank to reduce credit risk. The balance sheet constraint ensures that having picked the monitoring schedule and the covenant threshold, the loan interest rate is also determined. The tighter the credit standards, the lower the default risk and loss given default but the loan interest rate is lower and monitoring is costly. $\Pi$ is a continuous function on a bounded support and therefore attains a maximum. Note that there is no uncertainty faced by the bank.

Notwithstanding the relative simplicity of the problem, finding a solution is difficult and requires numerical methods. Why it is so difficult can be seen by observing how many times $\tilde{\psi}$ appears in equation (6). This term appears in the loan interest rate term, the default and voluntary exit thresholds and the invariant distributions.

As previously, much of the intuition can be seen in a simpler setting by considering the case in which the monitoring rate is common across all incumbent firms. It is also much easier to visualise as it can be illustrated in a three-dimension plot. Figure 4 illustrates the general case of an interior solution to the model based on a constant per unit cost of 
monitoring $m$ and loss given default $\lambda(a)=L-\gamma q(a)$ where $\gamma>1$. Discussion of the importance of the latter assumption is deferred to the following section on the general equilibrium properties of the model. The crucial point is that the bank is less efficient than the entrepreneur in running the project until it can be closed down. ${ }^{17}$ Figure 4 plots profits per loan in percentage points on the vertical axis against the monitoring intensity, $\varphi$, and the covenant threshold, $\zeta$. For interior solutions of the model, this is humped shaped with a unique profit maximising triplet $\{\rho, \varphi, \zeta\}$.

Corner solutions are also possible with respect to the monitoring intensity under different parameterisations. If $\varphi=0$, there is no monitoring and so the covenant threshold is irrelevant. Intuitively, $\varphi=0$ is profit-maximising if monitoring is very expensive, the bankruptcy cost is so high that the default is negligible or entry and exit costs are small (or any combination of the three). At the opposite extreme, there is full monitoring every period when $\varphi=1$. This is the full information case and the bank's covenant threshold, $\zeta$, is always binding. Naturally, this situation arises under the opposite conditions. Unique interior solutions occur over all intermediate ranges of these parameters.

What is the economic intuition behind the hump shape? First, fix a covenant threshold and consider increasing the monitoring intensity over $[0,1]$. With no monitoring, the equilibrium distribution of loans has the lowest credit quality, the highest default risk and the highest loss given default. But it is also the most valuable contract for the borrower since she has all the continuation right and therefore this contract commands the highest loan interest rate. At $\varphi=0$, there is high risk and a high loan premium but no monitoring cost. As monitoring increases, credit quality improves, loan interest rates fall and monitoring costs increase. For interior solutions, the reduction in equilibrium credit losses initially more than compensates for the lower loan spread and higher monitoring expenses but eventually this is reversed. The trade-off reverses because the marginal improvement in credit risk is decreasing.

This reduction in the marginal effectiveness of monitoring occurs because a higher monitoring rate induces a higher overall exit rate which must be matched in equilibrium by a higher entry rate. Since the marginal new entrants are of higher credit quality than the marginal exiting firm, this increases the average credit quality of the distribution, which is a benefit, but these new entrants are at low risk of default. As average distance to default declines, there is less marginal benefit to monitoring.

Now instead fix an intermediate value for $\varphi$ and consider increasing $\zeta$ over the range $\left[a_{X}(\psi), a_{E}(\psi)\right]$. At $\zeta=a_{X}(\psi)$, there are no firms below the covenant threshold at the time the bank monitors so it is redundant. Increasing the covenant threshold widens the net and thus allows the bank to eliminate some high risk firms but at the expense of a

17 The model is calibrated so that $q(a)$ is negative (ie gross losses) whenever default takes places. 
FIGURE 5. Optimal Monitoring Intensity

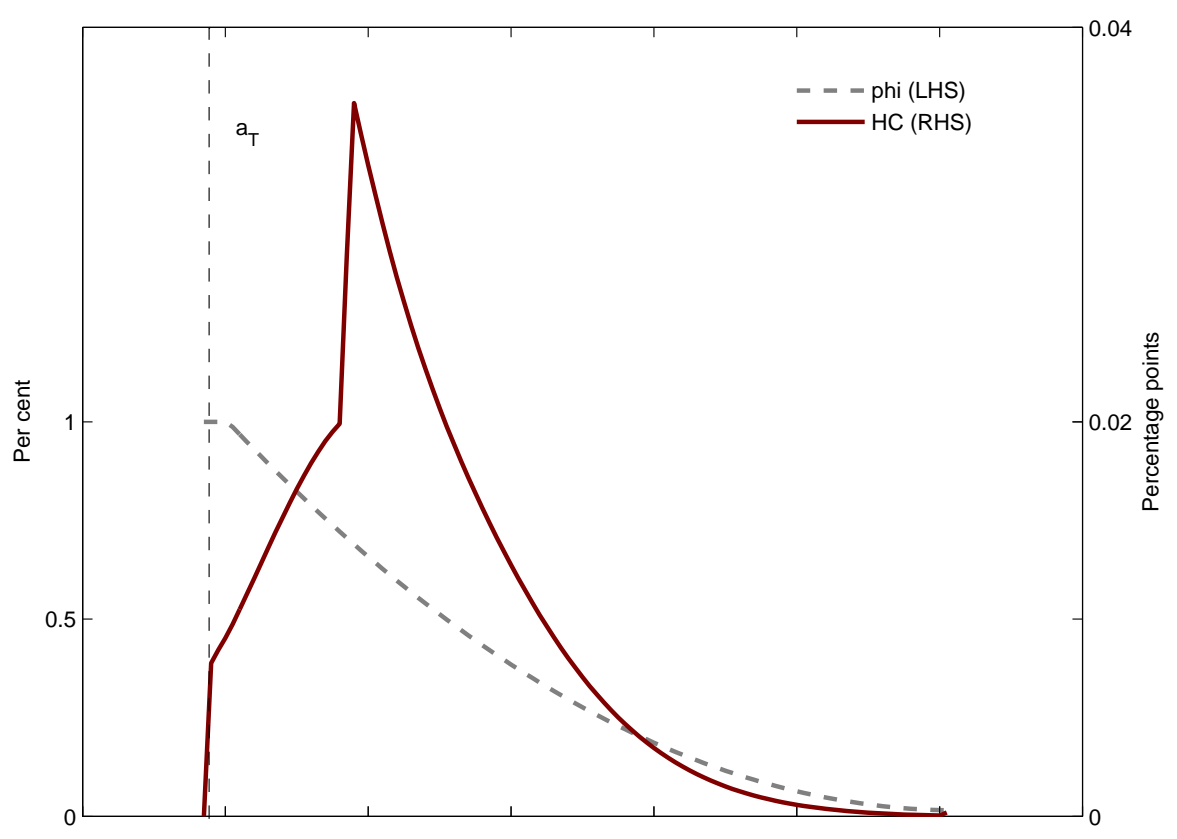

lower loan interest rate. However, if the covenant threshold is weak, then only very few firms will fail it and the bank will be monitoring a large number of firms that it allows to continue. In effect, the bank is paying for information it doesn't need. At the opposite extreme, at $\zeta=a_{E}(\psi)$, the bank is eliminating a lot of firms that are a large distance from default. It is also the least attractive contract from the point of view of the borrower and commands the lowest loan interest rate. The bank forgoes much interest margin to make marginal reductions in credit losses. For any given $\varphi$ the optimal $\zeta$ lies somewhere in between.

The preceding paragraphs highlight the inefficiency in using a common monitoring rate across all firms. Monitoring in that context is valuable only because it allows the bank to eliminate firms below the covenant threshold. Monitoring firms who are mostly likely to be above the threshold is inefficient so the bank would be better off trying to target its monitoring on firms likely to be below the threshold. In other words, the bank should monitor more intensely those firms that it suspects are relatively weak. But it will need to monitor to obtain the information used to target its monitoring. This is precisely the problem considered in the broader set-up of the model with state-contingent monitoring.

Finding a monitoring schedule in practice, however, is highly challenging and requires choosing a parameterised function. Figure 5 reports the results of an optimisation over a quadratic function using the same illustrative parameters as previously. ${ }^{18}$ The horizontal

18 Higher powered polynomials have essentially the same shape but take much longer to solve numerically. 
axis in this case is the last known state by the bank, the left-hand vertical axis is the monitoring intensity and the right-hand vertical axis is the measure of firms. The solid line represents the distribution of firms by last known state just before the idiosyncratic shock and the dashed line represents the monitoring rate chosen by the bank for firms in that last known state. The monitoring schedule is, of course, only relevant for values of the idiosyncratic state at or above the covenant threshold since firms found to be below that threshold are removed. As might be expected, the monitoring intensity decreases with last known state. The optimal schedule requires the bank to monitor firms last observed close to the covenant threshold at nearly $100 \%$ and monitor those at very high last known states at a negligible rate. The solid distribution indicates the measure of firms to which each monitoring rate applies.

Why does the bank choose to monitor some firms at a negligible rate even though it knows they will eventually (almost surely) exit, quite possibly through default? The bank, has has been mentioned before, monitors for two reasons. The direct benefit of monitoring is to discover those in breach of the covenant and remove them. The indirect benefit of monitoring is to target its monitoring more efficiently. Whenever the bank monitors a firm and finds it to be above the covenant threshold, it only gains this indirect benefit. If it is likely that the firm is currently a long way from the covenant threshold, then the bank is very unlikely to gain directly and only gains the indirect benefit. But the indirect benefit is a function of the likelihood of achieving the direct benefit. If the direct benefit is likely to be small, then so is the likely indirect benefit.

Consider what the bank is likely to find if it monitors a firm that it monitored last period and was found to be of very high profitability. Since this is a long way from the covenant threshold, it is unlikely that if it is monitored this period, it will be found to be in breach of the covenant. Given that idiosyncratic shocks decay gradually, the likelihood is that it will find the firm has experienced a mild decline in its profitability. According to the monitoring schedule, this will lead the bank to increase its monitoring probability by a small amount. But with only a modest new monitoring rate, the likelihood of gaining a future direct benefit is relatively small. If the direct benefit is negligible and the indirect gain is slight, then monitoring at a high rate is not worth the cost.

Figure 6 illustrates the two marginal cross-sectional distributions together. The solid line represents the distribution of firms by last known profitability state - the same distribution as in Figure 5. The dashed line represents the distribution of firms by actual current profitability state - the same distribution as in Figure 1. This re-emphasises the analysis in the preceding paragraphs. Since the bank monitors firms in the upper right tail very little, it does not update its knowledge of their states and therefore there are considerably less in that current state than in the distribution of last known state. By contrast, there are considerably more firms between the entry threshold and the bank 
FIGURE 6. Distributions by current and last known state

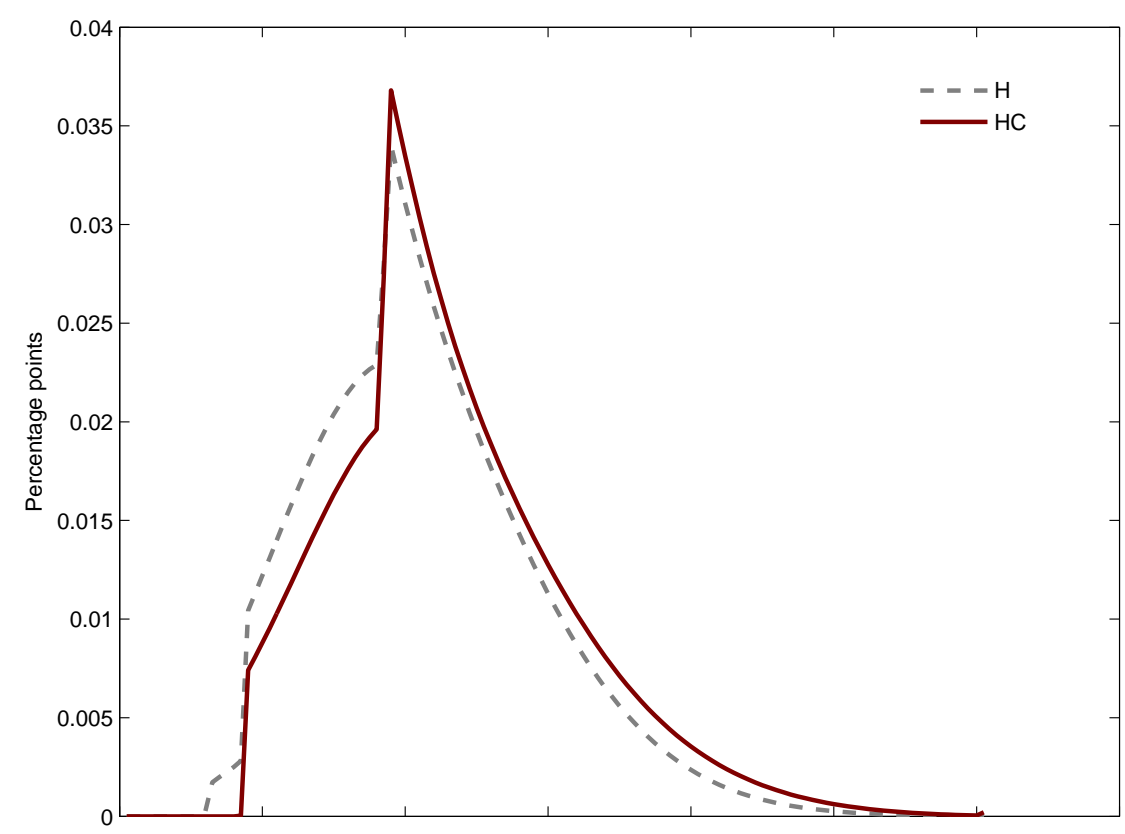

covenant threshold than is reflected in the distribution of last known states. Moreover, there is a modest mass of firms below the bank's covenant threshold who survive only because of the less than complete monitoring of the bank.

With a targeted monitoring rate, the image of the distribution based on the last known state is more creditworthy than is actually the case. However, it is important not to think of this as a bias or that the bank is mis-informed. The bank, in effect, knows that its distribution of credit risk is truly the dashed line and it knows that it is this distribution which generates its profits in equation (6). The weaker image is simply the result of the fact that monitoring is incomplete and thus the last known state is out of date to varying degrees. Since the firms that the bank monitors the least are the ones that have previously experienced the most positive idiosyncratic shocks and these shocks decay on average, the average out of date information on those firms is too positive.

\section{GenerAl EQUILIBRIUM PROPERTIES AND ROBUSTNESS}

The previous two sections have described the optimal choices of the agents and the decision by the bank. This section analyses the properties of equilibrium, explains the importance of several assumptions in deriving the results and hopefully provides economic intuition about how the various features of the model interact.

The bank makes a profit in this model because there is a positive loan spread. This margin can be divided into three components. 
First, there is an intermediation rent received by the bank because of the assumptions that inventors cannot lend directly to entrepreneurs, that the project size is fixed, that there is a monopoly bank and that the deposit rate is exogenously determined. ${ }^{19}$ This rent occurs because there is a utility gain in switching from being an inventor to being an entrepreneur because only the marginal entrant is indifferent between the two situations. In order to meet the balance sheet constraint, the bank has to change the relative attractiveness of being a depositor or borrower. With a fixed deposit rate, the bank changes the loan rate (in conjunction with the other credit terms) to equilibrate the balance sheet and earns the difference.

Second, borrowers pay for the option to declare bankruptcy. They do not do this explicitly but the fact that downside losses are capped increases the attractiveness of borrowing and must be constrained by a higher loan interest rate (than if bankruptcy were not available). If there was no efficiency loss when the bank liquidates the project - ie if $\lambda(a)=L-q(a)$ - then this bankruptcy option would be equally valued by both parties and the bank would be fairly compensated for the transfer of losses during bankruptcy. If loss given default is fully compensated, then the bank has no incentive to reduce equilibrium default risk in which case, since monitoring is costly and paid for by the bank, it would be optimal to set the monitoring rate to zero. Turning this around, only if bankruptcy is inefficient can there be an incentive to monitor. But inefficiency implies that the cost of the bankruptcy option to the bank is greater than the benefit to the borrower and therefore what the borrower is willing to pay will not compensate the bank for credit risk. This, of course, would seem to imply that risky lending loses money and that a private bank would not fund risky projects.

This explains the importance of the third component of the loan spread which is the insurance borrowers are willing to pay to avoid "premature"liquidation. To understand this premium, consider the situation in which entry and exit from production is costless ( $L=C=0$ ). From (7) if $C=L=0$, then $a_{E}=a_{X}$ (because monitoring is irrelevant in this case). Firms would simply start up when there is an expected profit for at least one period and shut down again whenever there is an expected loss the following period. Production would be completely opportunistic. But in the model, as in reality, firms cannot jump in and out of production like this. Start-up costs are a deterrent to entry and liquidation costs provide an incentive to absorb mild losses if there is sufficient prospect of a future return to profitability. The voluntary exit thresholds, $a_{X}($.$) (under \varphi(\alpha)$ ), are the points at which the prospect of recovery becomes too low. Exiting above those points entails a utility loss. Yet, as explained in the previous section, if the bank is to protect itself

19 Standard assumptions like positive and continuously decreasing returns to capital, flexible capital adjustment, free entry and exit and direct lending (or perfect banking competition) would together give all borrowers and lenders the same expected utility. 
against credit risk with a loan covenant, then this has to bite at above these voluntary exit thresholds and the greater the rate of monitoring, the less attractive the loan is to the borrower. Or put another way, the borrower is willing to pay an insurance premium against premature liquidation through a higher interest rate for a lower monitoring schedule.

There is an important relationship between this premature liquidation insurance premium and the bankruptcy premium. The insurance premium, per se, does not involve any additional risk to the bank. It would exist even if bankruptcy was efficient and credit risk was fully compensated. But the more insurance the bank offers, through a lower monitoring schedule, the lower the credit quality of the distribution (as was illustrated in Figure 3). So the insurance premium can only be earned by taking on default risk at the same time. It was explained above that if bankruptcy is inefficient, then the bankruptcy premium does not cover the credit risk. So it is the fact that the bank also earns the insurance premium that explains the willingness to offer risky loan contracts.

Joining up the threads of this discussion, monitoring and covenants are only relevant when bankruptcy is inefficient and when there are entry and exit frictions from production. It is the interplay between these two effects that determines equilibrium credit standards.

\section{CONCLUSION}

The model developed in this paper provides a theory of how banks manage credit risk when they make multi-period loans to entrepreneurs who have private information on firm profits and future prospects. If entry and exit were frictionless, then the individually rational choices of entrepreneurs and inventors would select the distribution of firms with the lowest credit risk and the asymmetry of information would have no bite. This is not the case with entry and exit costs since there will now be a segment of firms who choose to continue in circumstances in which they would not decide to start. Such firms are at the highest risk of defaulting in the near future and the bank has an interest in trying to reduce this portion of the distribution through its credit standards.

In the model, the bank monitored continuing loans stochastically using a scheduled based on the last known profitability state to discover breaches of a loan covenant. But credit controls are costly, directly due to the cost of monitoring and indirectly through the interest rate the bank can charge on loans. Credit standards are a form of control right over the decision to continue a firm - the tighter the standards, the less control exercised by the borrower. Borrowers, therefore, are willing to pay an interest rate premium for greater control rights. So in deciding how to set its credit standards, a bank needs to take into consideration the cost of monitoring and enforcing its covenants, the effect of credit standards on default risk and the loan interest rate it can charge for different contract 
terms. The model shows how these competing considerations can be equilibrated whilst ensuring that the bank has sufficient deposits to fund its lending. 


\section{REFERENCES}

BORDER, K. C., AND J. SObEL (1987): "Samurai Accountant: A Theory of Auditing and Plunder," Review of Economic Studies, 54(4), 525-40.

BROECKER, T. (1990): “Credit-worthiness tests and interbank competition," Econometrica, 58(2), 429-452.

Clementi, G. L., And H. A. Hopenhayn (2006): “A Theory of Financing Constraints and Firm Dynamics," The Quarterly Journal of Economics, 121(1), 229-265.

Dell'Ariccia, G., R. MARquez, And L. LAeven (2010): “Monetary Policy, Leverage, and Bank Risk-Taking," IMF Working Papers 10/276, International Monetary Fund.

DiAmond, D. W. (1984): “Financial Intermediation and Delegated Monitoring," Review of Economic Studies, 51(3), 393-414.

Djankov, S., R. L. Porta, F. Lopez-De-Silanes, And A. Shleifer (2002): “The Regulation Of Entry," The Quarterly Journal of Economics, 117(1), 1-37.

Foster, L., J. HAltiWAnger, And C. Syverson (2008): “Reallocation, Firm Turnover, and Efficiency: Selection on Productivity or Profitability?," American Economic Review, 98(1), 394-425.

Gale, D., ANd M. Hellwig (1985): "Incentive-Compatible Debt Contracts: The OnePeriod Problem," Review of Economic Studies, 52(4), 647-63.

Hopenhayn, H. A. (1992): "Entry, Exit, and Firm Dynamics in Long Run Equilibrium," Econometrica, 60(5), 1127-50.

Kolmogorov, A., And S. Fomin (1970): Introductory Real Analysis. Dover Publications, New York.

MCCALL, J. J. (1970): “Economics of Information and Job Search," The Quarterly Journal of Economics, 84(1), 113-26.

MONnET, C., AND E. QUINTIN (2005): “Optimal contracts in a dynamic costly state verification model," Economic Theory, 26(4), 867-885.

PenAlver, A. (2014): "Pre-crisis credit standards: monetary policy or the savings glut?," Working Paper 519, Banque de France.

RameY, V. A., And M. D. Shapiro (2001): “Displaced Capital: A Study of Aerospace Plant Closings," Journal of Political Economy, 109(5), 958-992.

RUCKES, M. (2004): "Bank competition and credit standards," Review of Financial Studies, 17(4), 1073-1102.

TAUCHEN, G. (1986): “Finite state markov-chain approximations to univariate and vector autoregressions," Economics Letters, 20(2), 177-181.

TOWNSEND, R. M. (1979): “Optimal contracts and competitive markets with costly state verification," Journal of Economic Theory, 21(2), 265-293.

Williamson, S. D. (1986): “Costly monitoring, financial intermediation, and equilibrium credit rationing," Journal of Monetary Economics, 18(2), 159-179. 


\section{ApPENdix A. PROOFS OF PROPOSITIONS}

Proposition 1 Given Assumptions I, II and III and a banking contract $\psi$, unique, bounded and mutually consistent functions $V(E, a, \alpha ; \psi, V(I))$ and $V(I, a ; \psi, V(E))$ exist.

Proof. It greatly simplifies the presentation of the proof (and with no loss of generality) to ignore the presence of the default option and focus on the choices of voluntary entry, exit and continuation. We work in $\mathcal{B}(A)$, the set of all bounded functions on the set $A$ and $\mathcal{B}(A \times A)$, the set of all bounded functions on the set $A \times A$ and with the sup norm. For any $V(E) \equiv V(E, a, \alpha) \in \mathcal{B}(A \times A)$, the operator associated with $V(I)$

$$
T_{1}(V(E), V(I))(a)=\max \left\{\begin{array}{c}
r_{d}+\beta E[V(I)], \\
\int_{0}^{1}\left[q\left(a^{\prime}\right)-r+\beta V\left(E, a^{\prime}, a\right)\right] F\left(d a^{\prime}, a\right)-C
\end{array}\right\}
$$

satisfies Blackwell's sufficient conditions for a contraction on $\mathcal{B}(A)$ with modulus $\beta$ and a unique $V(I)$ exists for a given $V(E)$ with

$$
V(I)=T_{1}(V(E), V(I))
$$

Likewise, for any $V(I) \in \mathcal{B}(A)$, the operator

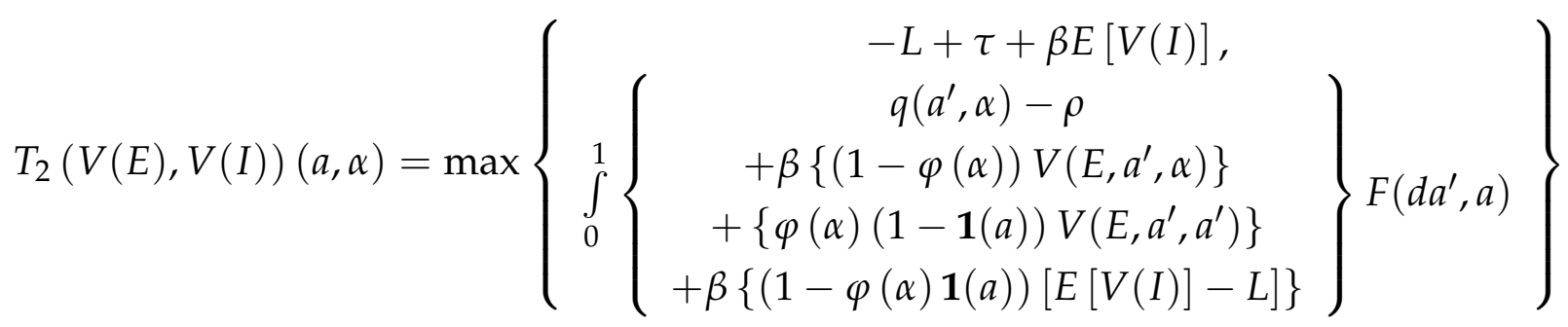

is a contraction with modulus $\beta$ and therefore a unique $V(E)$ exists for a given $V(I)$ with

$$
V(E)=T_{2}(V(E), V(I))
$$

The existence of each value function individually does not, however, imply the existence or uniqueness of any pair of functions $(V(E), V(I))$ satisfying both conditions (11) and (12) simultaneously. For any $V(I), V(I)^{\prime} \in \mathcal{B}(A)$ and $V(E), V(E)^{\prime} \in \mathcal{B}(A \times A)$

$$
\begin{gathered}
\left|\int_{A}\left[V(I)\left(a^{\prime} ; .\right)-V(I)^{\prime}\left(a^{\prime} ; .\right)\right] G\left(d a^{\prime}\right)\right| \leq\left\|V(I)-V(I)^{\prime}\right\| \\
\left|\int_{A}\left[V(E)(a \prime ;,)-V(E)^{\prime}(a \prime ;,)\right] F(d a \prime, a)\right| \leq\left\|V(E)-V(E)^{\prime}\right\|
\end{gathered}
$$


and

$\left|\int_{0}^{1}\left\{\begin{array}{c}(1-\varphi(\alpha))\left[V\left(E, a^{\prime}, \alpha\right)-V^{\prime}\left(E, a^{\prime}, \alpha\right)\right] \\ +\varphi(\alpha)(1-\mathbf{1}(a))\left[V\left(E, a^{\prime}, a^{\prime}\right)-V^{\prime}\left(E, a^{\prime}, a^{\prime}\right)\right] \\ +(1-\varphi(\alpha) \mathbf{1}(a))\left[E[V(I)]-E\left[V^{\prime}(I)\right]\right]\end{array}\right\} F\left(d a^{\prime}, a\right)\right| \leq \max \left(\begin{array}{c}\left\|V(I)-V(I)^{\prime}\right\|, \\ \left\|V(E)-V(E)^{\prime}\right\|\end{array}\right)$

where $\|v\|=\sup _{a}|v(a)|$ is the usual sup norm. Let $\mathcal{M}$ be the set of ordered pairs $(V(E), V(I))$ such that $V(E)$ is in $\mathcal{B}(A \times A)$ and $V(I)$ is in $\mathcal{B}(A)$ and impose the following metric $d$ on $\mathcal{M}$ :

$$
d\left((V(E), V(I)),\left(V^{\prime}(E), V^{\prime}(I)\right)\right)=\beta \max \left\{\left\|V(E)-V(E)^{\prime}\right\|,\left\|V(I)-V(I)^{\prime}\right\|\right\}
$$

Now consider the operator $T: \mathcal{M} \rightarrow \mathcal{M}$ defined by

$$
T\left(V_{E}, V_{I}\right)=\left(T_{1}(V(E), V(I)), T_{2}(V(E), V(I))\right)
$$

Fix $a \in A$ and observe that

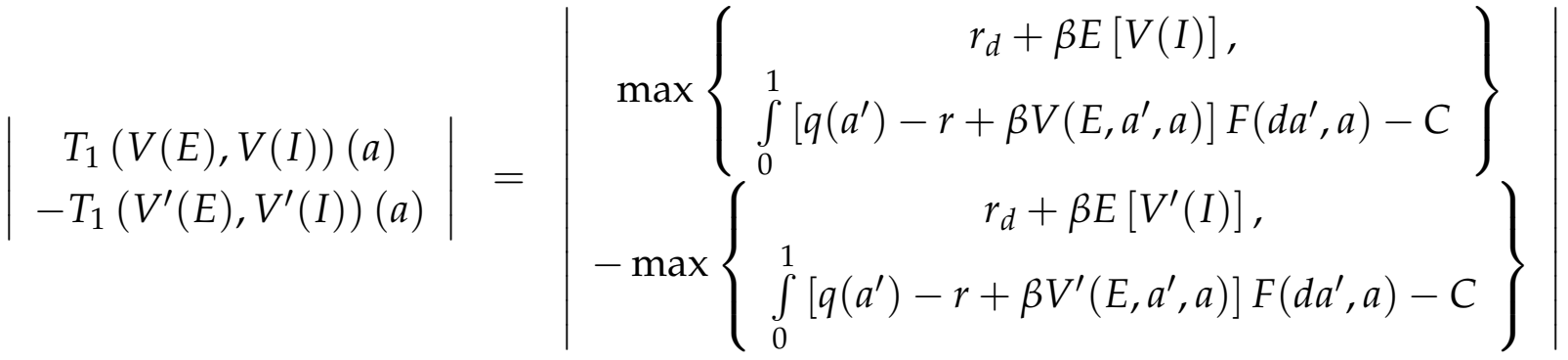

$$
\begin{aligned}
& \leq \max \left\{\mid \begin{array}{c}
\int_{0}^{1}\left[q\left(a^{\prime}\right)-r+\beta V\left(E, a^{\prime}, a\right)\right] F\left(d a^{\prime}, a\right)-C \\
-\left[\int_{0}^{1}\left[q\left(a^{\prime}\right)-r+\beta V^{\prime}\left(E, a^{\prime}, a\right)\right] F\left(d a^{\prime}, a\right)-C\right] \\
\left|r_{d}+\beta E[V(I)]-r_{d}+\beta E\left[V^{\prime}(I)\right]\right|
\end{array}\right\} \\
& =\beta \max \left\{\begin{array}{c}
\left|\int_{0}^{1}\left[V\left(E, a^{\prime}, a\right)-V^{\prime}\left(E, a^{\prime}, a\right)\right] F\left(d a^{\prime}, a\right)\right|, \\
\left|E[V(I)]-E\left[V^{\prime}(I)\right]\right|
\end{array}\right\} \\
& \leq \beta \max \left\{\left\|V(E)-V^{\prime}(E)\right\|,\left\|V(I)-V^{\prime}(I)\right\|\right\}
\end{aligned}
$$

where the first inequality follows from the fact that $|\max (a, b)-\max (c, d)| \leq \max (|a-c|,|b-d|)$ for any $a, b, c, d \in \mathbb{R}$.Taking the supremum over both sides:

$\left\|T_{1}(V(E), V(I))(a)-T_{1}\left(V^{\prime}(E), V^{\prime}(I)\right)(a)\right\| \leq \beta \max \left\{\left\|V(E)-V^{\prime}(E)\right\|,\left\|V(I)-V^{\prime}(I)\right\|\right\}$

Similar arguments give

$\left\|T_{2}(V(E), V(I))(a, \alpha)-T_{2}\left(V^{\prime}(E), V^{\prime}(I)\right)(a, \alpha)\right\| \leq \beta \max \left\{\left\|V(E)-V^{\prime}(E)\right\|,\left\|V(I)-V^{\prime}(I)\right\|\right\}$

and thus

$$
d\left(T(V(E), V(I)), T\left(V^{\prime}(E), V^{\prime}(I)\right)\right) \leq \beta d\left((V(E), V(I)),\left(V^{\prime}(E), V^{\prime}(I)\right)\right)
$$


Hence $T$ is a contraction mapping on the complete metric space $(\mathcal{M}, d)$ establishing a unique fixed point exists. $V(E, a, \alpha)$ and $V(I, a)$ are unique continuous functions.

Proposition 2 These value functions yield unique and continuous functions in $\psi$ for the entry threshold $a_{E}$ and exit thresholds $a_{X}(\alpha) . a_{E}(\psi)$ and $a_{X}(\psi, \alpha)$ are both strictly increasing in $\psi$.

Proof. To show that the threshold functions are strictly increasing in $\psi$, consider the effect of a reduction in $\rho$ on $a_{X}(\psi, \alpha)$. To simplify the exposition, ignore the bank threshold and the default option, and set $\tau=C=L=0$. These simplifications give the following value function for the agents conditional on a given $\rho$

$$
V(a ; \rho)=\max \left\{\beta \int V(a, \rho) G(a), \int\left(a^{\prime}-\rho+\beta V\left(a^{\prime}, \rho\right)\right) F\left(a^{\prime}, a\right)\right\}
$$

Note that under the simplifying conditions the pre-determined endogenous state is irrelevant and there is only one value function. Note also that under these simplifications, the exit threshold conditional on $\rho$ is also the entry threshold $\hat{a}(\rho)$, defined implicitly by:

$$
\int\left(a^{\prime}-\rho+\beta V\left(a^{\prime}, \rho\right)\right) F\left(a^{\prime}, \hat{a}(\rho)\right)=\beta \int V(a, \rho) G(a)=\beta E V(\rho)
$$

where $E V(\rho)$ denotes the expected value of being an inventor in the current period. Consider a rise in $\rho$ to $\tilde{\rho}$. We are thus seeking a new $\hat{a}(\tilde{\rho})$ that satisfies

$$
\int\left(a^{\prime}-\tilde{\rho}+\beta V\left(a^{\prime}, \tilde{\rho}\right)\right) F\left(a^{\prime}, \hat{a}(\tilde{\rho})\right)=\beta E V(\tilde{\rho})
$$

To show $\hat{a}(\tilde{\rho})>\hat{a}(\rho)$, take equation (14), fix $\hat{a}(\rho)$ and consider what happens to both sides as $\rho$ rises to $\tilde{\rho}$. To do so, we need to solve for the value functions. Iterate on the entry option to obtain:

$$
\int\left(a^{\prime}-\rho+\beta V\left(a^{\prime}\right)\right) F\left(a^{\prime}, a\right)=\Lambda(a)-\mathrm{Y}(a) \rho+\Delta(a) \beta E V
$$

where

$$
\begin{gathered}
\Lambda(a)=\int a^{\prime} F\left(a^{\prime}, a\right)+\beta \int_{\hat{a}}^{1} \int a^{\prime \prime} F\left(a^{\prime \prime}, a^{\prime}\right) F\left(a^{\prime}, a\right)+\beta^{2} \int_{\hat{a}}^{1} \int_{\hat{a}}^{1} \int a^{\prime \prime \prime} F\left(a^{\prime \prime \prime}, a^{\prime \prime}\right) F\left(a^{\prime \prime}, a^{\prime}\right) F\left(a^{\prime}, a\right)+\ldots \\
\mathrm{Y}(a)=1-\beta[1-F(\hat{a}, a)]-\beta^{2} \int_{\hat{a}}^{1}\left[1-F\left(\hat{a}, a^{\prime}\right)\right] F\left(a^{\prime}, a\right)+\ldots
\end{gathered}
$$

and

$$
\Delta(a)=\beta F(\hat{a}, a)+\beta^{2} \int_{\hat{a}}^{1} F\left(\hat{a}, a^{\prime}\right) F\left(a^{\prime}, a\right)+\ldots
$$

$\Lambda(a)$ is the discounted expected value of future profits where the survival probability is conditional on $a$. $\mathrm{Y}(a)$ is the survival-weighted discount present value factor. Both $\Lambda(a)$ and $\mathrm{Y}(a)$ are strictly increasing in $a . \Delta(a)$ is the discount factor associated with the probability of exit. 
Denote $p(a)(i)$ the probability of exiting in $i$ period's time given starting state $a$. Therefore

$$
\begin{aligned}
\mathrm{Y}(a) & =1+\beta[1-p(a)(1)]+\beta^{2}[1-p(a)(1)-p(a)(2)]+\beta^{3}[1-p(a)(1)-p(a)(2)-p(a)(3)] \\
& =1+\beta+\beta^{2}+\beta^{3} \ldots-\beta\left[1+\beta+\beta^{2}+\beta^{3} \ldots\right] p(a)(1)-\beta^{2}\left[1+\beta+\beta^{2}+\beta^{3} \ldots\right] p(a)(2) \ldots \\
& =\frac{1}{1-\beta}\left[1-\beta p(a)(1)-\beta^{2} p(a)(2) \ldots\right]
\end{aligned}
$$

and

$$
\begin{aligned}
\Delta(a) & =\beta F(\hat{a}, a)+\beta^{2} \int_{\hat{a}}^{1} F\left(\hat{a}, a^{\prime}\right) F\left(a^{\prime}, a\right)+\beta^{3} \int_{\hat{a}}^{1} \int_{\hat{a}}^{1}\left[1-F\left(\hat{a}, a^{\prime \prime}\right)\right] F\left(a^{\prime \prime}, a^{\prime}\right) F\left(a^{\prime}, a\right) \\
& =\beta p(a)(1)+\beta^{2} p(a)(2)+\beta^{3} p(a)(3) \ldots .
\end{aligned}
$$

Thus $\mathrm{Y}(a)=\frac{1}{1-\beta}[1-\Delta(a)] \forall a$

Now we iterate on the inventors continuation option to obtain

$$
\beta E V(\rho)=\frac{\beta \int_{\hat{a}}^{1}[\Lambda(a)-\mathrm{Y}(a) \rho] G(a)}{1-\beta G(\hat{a})-\beta \int_{\hat{a}}^{1} \Delta(a) G(a)}
$$

The numerator of this expression is the expected value of the conditional expected discounted present value of profits. This will be equal to the integral of the invariant distribution of profits. The denominator of this expression is the discount factor applied to this expected stream reflecting the distribution over future dates during which a currently waiting agent will be in production. Now define $\bar{Y}[1-G(\hat{a})]=\int_{\hat{a}}^{1} \mathrm{Y}(a) G(a)$ and $\bar{\Delta}[1-G(\hat{a})]=\int_{\hat{a}}^{1} \Delta(a) G(a)$ The derivative of the waiting option with respect to a rise in $\rho$ for a fixed $\hat{a}$ is

$$
\frac{\partial \beta E V(\rho)}{\partial \rho}=-\frac{\beta \bar{Y}[1-G(\hat{a})]}{1-\beta G(\hat{a})-\beta \bar{\Delta}[1-G(\hat{a})]}=-\frac{\bar{Y}}{\frac{1-\beta G(\hat{a})}{\beta-\beta G(\hat{a})}-\bar{\Delta}}
$$

The derivative of the entering option at $\hat{a}$ to a rise in $\rho$ for a fixed $\hat{a}$ is

$$
\frac{\partial[\Lambda(\hat{a})-\mathrm{Y}(\hat{a}) \rho+\Delta(\hat{a}) \beta E V(\rho)]}{\partial \rho}=-\mathrm{Y}(\hat{a})+\Delta(\hat{a}) \beta \frac{\partial E V(\rho)}{\partial \rho}
$$

This option is more sensitive (ie falls by more) if

$$
(\Delta(\hat{a})-1) \frac{\partial \beta E V(\rho)}{\partial \rho}<\mathrm{Y}(\hat{a})
$$

Since $\Delta(\hat{a})-1<0$, then the condition to be satisfied is

$$
\frac{\partial \beta E V(\rho)}{\partial \rho}>\frac{\mathrm{Y}(\hat{a})}{\Delta(\hat{a})-1}
$$

From above, this is

$$
\frac{\partial \beta E V(\rho)}{\partial \rho}>-\frac{1}{1-\beta}
$$


Also from above

$$
\begin{aligned}
\frac{\partial \beta E V(\rho)}{\partial \rho} & =-\frac{\bar{Y}}{\frac{1-\beta G(\hat{a})}{\beta-\beta G(\hat{a})}-\bar{\Delta}} \\
& =-\frac{1}{1-\beta} \frac{[1-\bar{\Delta}(a)]}{\frac{1-\beta G(\hat{a})}{\beta-\beta G(\hat{a})}-\bar{\Delta}}
\end{aligned}
$$

Thus the condition is satisfied provided

$$
1<\frac{1-\beta G(\hat{a})}{\beta-\beta G(\hat{a})}
$$

which is true since $\beta<1$.

Therefore the entry option is more sensitive to the rise in the interest rate than the waiting option for a fixed $\hat{a}(\rho)$. As a result

$$
\int\left(a^{\prime}-\tilde{\rho}+\beta V\left(a^{\prime}, \tilde{\rho}\right)\right) F\left(a^{\prime}, \hat{a}(\rho)\right)<\beta E V(\tilde{\rho})
$$

for $\tilde{\rho}>\rho$ and $\hat{a}(\rho)$. This requires $\hat{a}(\tilde{\rho})>\hat{a}(\rho)$ to equilibrate the rise in $\rho$. This condition carries over to the more complex model with entry and exit costs, bankruptcy and the bank covenant with monitoring.

Proposition 3 For each $\psi$ and given $N$ there is a unique invariant distribution, $\bar{H}(\psi)$

Proof. $H(\psi)$ is a distribution measure on the compact measurable space $(A \times A)$. For borel sets $Q \times R$ in $A \times A$ define

$$
\hat{P}(a, \alpha, Q, R ; \psi)=\mathbf{1}(\alpha, R)(1-\varphi(\alpha)) \int_{Q \cap Y(\psi, \alpha)} F(d q, a)+\varphi(\alpha) \int_{Q \cap R \cap Z(\psi, \alpha)} F(d q, a)
$$

and

$$
g(Q, R, \psi)=\int_{Q \cap R \cap W(\psi)} G(d s)
$$

$\mathbf{1}(\alpha, R)$ is an indicator function taking the value 1 if $\alpha \in R$ and 0 otherwise. $W(\psi)=$ $\left\{a^{\prime}: a^{\prime} \geq a_{E}(\psi)\right\}, Y(\psi, \alpha)=\left\{a^{\prime}: a^{\prime} \geq a_{T}(\psi, \alpha)\right\}$ and $Z(\psi, \alpha)=\left\{a^{\prime}: a^{\prime} \geq a_{X}(\psi, \alpha)\right\} . \hat{P}(a, X ; \psi)$ defies a bounded linear operator on the space of positive bounded measures defined by $\hat{P} H(Q, R)=\int \hat{P}(a, \alpha, Q, R ; \psi) H(d a)$ for all borel sets $Q \times R$ in $A \times A$ with operator norm $\|\hat{P}\| \leq 1$.

The transition equation (6) for the full cross-sectional distribution can be re-written (following Hopenhayn (1992) p. 1132) as

$$
H^{\prime}(\psi)=\hat{P}(\psi) H(\psi)+N g(\psi)
$$

The monotone mixing assumption, I(iii), plus the presence of a positive exit rate ensure that $\left\|\hat{P}^{n}(\psi)\right\|<1$ where $\hat{P}^{n}(\psi)$ is the $\mathrm{n}$-fold composition of $\hat{P}(\psi), \hat{P}^{0}(\psi)=I$, the identity operator and $\|$.$\| is the operator norm. As a result, following Hopenhayn (1992) drawing$ 
on Kolmogorov and Fomin (1970) $\left(I-\hat{P}^{n}(\psi)\right)^{-1}=\sum_{t=0}^{\infty} \hat{P}^{n t}(\psi)$ and since $\left\|\hat{P}^{n}(\psi)\right\|<1$ is non-increasing in $n,(I-\hat{P}(\psi))^{-1}$ also exists and

$$
\bar{H}(\psi)=N(I-\hat{P}(\psi))^{-1} g(\psi)
$$

is the unique invariant distribution given $\psi$ and $N$.

Proposition 4 There is a unique value $\tilde{\rho}$ that ensures that the balance sheet of the bank is equal on both sides for given values of $\varphi(\alpha)$ and $\zeta$.

Proof. For any $\varphi(\alpha)$ and $\zeta$ there is a unique invariant distribution $\bar{H}(\psi)$ for any $N$ from Proposition 3. However, in equilibrium we require

$$
N=\bar{H}(A, A ; \psi)=\frac{1}{2}
$$

which will not be the case for arbitrary $\psi$. Write the invariant distribution for $\rho$ and $N=\frac{1}{2}$ as

$$
\bar{H}(\rho)=\frac{1}{2}(I-\hat{P}(\rho))^{-1} g(\rho)
$$

and the entry distribution for $\rho$ as

$$
g(Q, R, \rho)=\int_{Q \cap R \cap W(\rho)} G(d a)
$$

Now write the invariant distribution for $\rho^{\prime}>\rho$ and $N=\frac{1}{2}$

$$
\bar{H}\left(\rho^{\prime}\right)=\frac{1}{2}\left(I-\hat{P}\left(\rho^{\prime}\right)\right)^{-1} g\left(\rho^{\prime}\right)
$$

and the entry distribution for $\rho^{\prime}$ as

$$
g\left(Q, R, \rho^{\prime}\right)=\int_{Q \cap R \cap W\left(\rho^{\prime}\right)} G(d a)
$$

The difference between the two $P$ operators can be written as

$$
\begin{aligned}
\tilde{P}\left(a, \alpha, Q, R ; \rho, \rho^{\prime}\right) & =\hat{P}(a, \alpha, Q, R ; \rho)-\hat{P}\left(a, \alpha, Q, R ; \rho^{\prime}\right) \\
& =\mathbf{1}(\alpha, R)(1-\varphi(\alpha)) \int_{Q \cap\left[Y\left(\rho^{\prime}, \alpha\right) \backslash Y(\rho, \alpha)\right]} F(d q, a)+\varphi(\alpha) \int_{Q \cap R \cap\left[Z\left(\rho^{\prime}, \alpha\right) \backslash Z(\rho, \alpha)\right]} F(d q, a)
\end{aligned}
$$

and likewise

$$
\mu\left(Q, R, \rho, \rho^{\prime}\right) \equiv g(Q, R, \rho)-g\left(Q, R, \rho^{\prime}\right)=\int_{Q \cap R \cap\left[W\left(\rho^{\prime}\right) \backslash W(\rho)\right]} G(d a)
$$

Since, $Y\left(\rho^{\prime}, \alpha\right) \subset Y(\rho, \alpha)$ and $Z\left(\rho^{\prime}, \alpha\right) \subset Z(\rho, \alpha), \tilde{P}\left(a, \alpha, Q, R ; \rho, \rho^{\prime}\right)$ is also a bounded linear operator and $\tilde{P} H(A, A)=\int \tilde{P}\left(a, \alpha, A, A ; \rho, \rho^{\prime}\right) H(d a)>0$. Likewise since $W\left(\rho^{\prime}\right) \subset$ $W(\rho), \mu\left(A, A, \rho, \rho^{\prime}\right)>0$. 
Thus

$$
\begin{aligned}
{[I-\hat{P}(\rho)]^{-1} } & =\sum_{t=0}^{\infty} \hat{P}^{t}(\rho) \\
& =\left[\hat{P}\left(\rho^{\prime}\right)+\tilde{P}\left(\rho, \rho^{\prime}\right)\right]^{0}+\left[\hat{P}\left(\rho^{\prime}\right)+\tilde{P}\left(\rho, \rho^{\prime}\right)\right]^{1}+\left[\hat{P}\left(\rho^{\prime}\right)+\tilde{P}\left(\rho, \rho^{\prime}\right)\right]^{2} \ldots \\
& =\hat{P}^{0}\left(\rho^{\prime}\right)+\hat{P}^{1}\left(\rho^{\prime}\right)+\hat{P}^{2}\left(\rho^{\prime}\right) \ldots+P P\left(\rho, \rho^{\prime}\right) \\
& =\left[I-\hat{P}\left(\rho^{\prime}\right)\right]^{-1}+P P\left(\rho, \rho^{\prime}\right)
\end{aligned}
$$

where $P P$ is a linear operator collecting all the miscellaneous terms. $P P H(A)=\int P P\left(a, A ; \rho, \rho^{\prime}\right) H(d a)$ 0 through the properties of $\hat{P}\left(\rho^{\prime}\right)$ and $\tilde{P}\left(\rho, \rho^{\prime}\right)$. Therefore

$$
\begin{aligned}
\bar{H}(\rho) & =\frac{1}{2}(I-\hat{P}(\rho))^{-1} g(\rho) \\
& =\frac{1}{2}\left[\left[I-\hat{P}\left(\rho^{\prime}\right)\right]^{-1}+P P\left(\rho, \rho^{\prime}\right)\right]\left[g\left(\rho^{\prime}\right)+\mu\left(\rho, \rho^{\prime}\right)\right] \\
& =\frac{1}{2}\left[I-\hat{P}\left(\rho^{\prime}\right)\right]^{-1} g\left(\rho^{\prime}\right)+\frac{1}{2}\left[I-\hat{P}\left(\rho^{\prime}\right)\right]^{-1} \mu\left(\rho, \rho^{\prime}\right)+\frac{1}{2} P P\left(\rho, \rho^{\prime}\right)\left[g\left(\rho^{\prime}\right)+\mu\left(\rho, \rho^{\prime}\right)\right] \\
& =\bar{H}\left(\rho^{\prime}\right)+\frac{1}{2}\left[I-\hat{P}\left(\rho^{\prime}\right)\right]^{-1} \mu\left(\rho, \rho^{\prime}\right)+\frac{1}{2} P P\left(\rho, \rho^{\prime}\right)\left[g\left(\rho^{\prime}\right)+\mu\left(\rho, \rho^{\prime}\right)\right]
\end{aligned}
$$

The second and third terms have positive measure and thus $\bar{H}(\rho)>\bar{H}\left(\rho^{\prime}\right)$. These terms are all continuous and strictly increasing in $\rho^{\prime}$ so by the intermediate value theorem there is a unique value at which $\tilde{H}(\rho)=N=\frac{1}{2}$.

\section{APPENDix B. MODEL PARAMETERISATION}

This is a stylised model that is intended to demonstrate a mechanism rather than replicate empirical data. The parameters of the illustrative numerical example are a mixture of calibration from direct model counterparts and trial and error for the rest to deliver plausible values for the loan interest rate, entry and exit rate of firms, default rate and loss given default. Yet at the same time, the model needs relatively modest "curvature" so that the mechanism is clearly visible in the illustrations. The example uses a normal distribution for $G(a)$ and an $\operatorname{AR}(1)$ process for $F\left(a, a^{\prime}\right)$ using a Tauchen matrix approximation (see Tauchen (1986)). The values of the idiosyncratic shock process comes from Foster, Haltiwanger, and Syverson (2008) (FHS). 
TABLE I. EQUILIBRIUM OUTCOMES

\begin{tabular}{llcl}
\hline \hline Parameter & Description & Value & Source \\
\hline & & & \\
$\beta$ & discount rate & 0.975 & \\
$\tau$ & deposit rate & $3.5 \%$ & \\
$\rho$ & idiosyncratic shock persistence & 0.9 & FHS Table 3 Demand shock persistence \\
$\sigma$ & idiosyncratic shock st dev & 0.2 & FHS Table 1 Price and TFP \\
$\mathrm{C}$ & entry cost & 0.3 & \\
$\mathrm{~L}$ & exit cost & 0.3 & \\
$\mathrm{BO}$ & bankruptcy cost & 0.4 & \\
$\mathrm{~m}$ & monitoring cost & 0.006 & \\
$\lambda$ & bank excess loss & 4 & \\
\hline \hline
\end{tabular}




\section{Documents de Travail}

600. M. Mogliani and T. Ferrière, "Rationality of announcements, business cycle asymmetry, and predictability of revisions. The case of French GDP” September 2016

601. R. S.J. Koijen; F. Koulischer; B. Nguyen and M. Yogo, “Quantitative Easing in the Euro Area: The Dynamics of Risk Exposures and the Impact on Asset Prices” September 2016

602. O. de Bandt and M. Chahad, “A DGSE Model to Assess the Post-Crisis Regulation of Universal Banks” September 2016

603. C. Malgouyres, "The Impact of Chinese Import Competition on the Local Structure of Employment and Wages: Evidence from France” September 2016

604. G. Cette, J. Lopez and J. Mairesse, “Labour market regulations and capital labour substitution” October 2016

605. C. Hémet and C. Malgouyres, “Diversity and Employment Prospects: Neighbors Matter!” October 2016

606. M. Ben Salem and B. Castelletti-Font, "Which combination of fiscal and external imbalances to determine the longrun dynamics of sovereign bond yields?” November 2016

607. M. Joëts, V. Mignon and T. Razafindrabe, "Does the volatility of commodity prices reflect macroeconomic uncertainty?” November 2016

608. M. Bussière, G. Gaulier and W. Steingress, "Global Trade Flows: Revisiting the Exchange Rate Elasticities" November 2016

609. V.Coudert and J. Idier, “An Early Warning System for Macro-prudential Policy in France” November 2016

610. S. Guilloux-Nefussi, “Globalization, Market Structure and Inflation Dynamics” December 2016

611. S.Fries, J-S. Mésonnier, S. Mouabbi, and J-P. Renne, "National natural rates of interest and the single monetary policy in the Euro Area” December 2016

612. J. Blaum, C. Lelarge and M. Peters, “The Gains from Input Trade with Heterogeneous Importers” December 2016

613. A. Penalver, “Optimal Monitoring of Long-Term Loan Contracts” December 2016

Pour accéder à la liste complète des Documents de Travail publiés par la Banque de France veuillez consulter le site : www.banque-france.fr

For a complete list of Working Papers published by the Banque de France, please visit the website:

www.banque-france.fr

Pour tous commentaires ou demandes sur les Documents de Travail, contacter la bibliothèque de la Direction Générale des Études et des Relations Internationales à l'adresse suivante :

For any comment or enquiries on the Working Papers, contact the library of the Directorate General Economics and International Relations at the following address :

BANQUE DE FRANCE

49- 1404 Labolog

75049 Paris Cedex 01

tél : 0033 (0)14297 7724 ou 0142926340 ou 4890 ou 6981

email : 1404-ut@banque-france.fr 